\title{
The influence of duplex vacuum-plasma treatment on the mechanics of complex-profile cutting tool wearing in the production of aircraft engine parts
}

\author{
Valeriy Kuzin, Vladimir Gurin, Alexander Shein ${ }^{*}$, Anastasiya Kochetkova, and Mariya Mikhailova \\ Moscow State University of Technology "STANKIN", 1 Vadkovsky per., GSP-4, Moscow 127994, Russian Federation
}

Received: 11 December 2018 / Accepted: 31 January 2019

\begin{abstract}
The paper presents a series of experimental results for assessing the effect of duplex vacuum-plasma processing as sequential ion nitriding and coating $(\mathrm{Nb}-\mathrm{Ti}-\mathrm{Al}-\mathrm{V}) \mathrm{N}$ on the characteristics of the surface layer and the wear rate of complex profile tools as herringbone broaches and gear-shaping cutters from high-speed steels powder during machining a heat-resistant nickel-based alloy. The rational duplex processing modes for each type of multi-profile cutting tool under investigation were established. Tests of the tool after duplex processing under conditions close to those encountered in production showed an increase in the operational durability of herringbone broaches and gear-shaping cutters up to two times in comparison with the original tool.
\end{abstract}

Keywords: Ion nitriding / coating / herringbone broach / gear-shaping cutter / operational durability / cutting tool / wear

\section{Introduction}

The production practice shows that the quality, accuracy, productivity, and cost of manufacturing of engineering products primarily depend on properties of used metalworking tool. Even with the use of the most advanced machine tool equipment, it is impossible to achieve high technical and economic indicators of the machining process with inadequate quality of metalworking tools. A metalworking tool is a particular object of machining technology. A variety of operating conditions cause various types of damage and failures of the technological system, and the tool wear rate is much higher than the wear rate of parts and components of machines. Therefore, the operability of the technological system as a whole primarily depends on the quality of the used metalworking tool.

As a confirmation of the issues mentioned above, it is possible to give an expert assessment that in the metalworking industry at least $60 \%$ of the total number of defective parts is caused by the insufficient quality of the tool. In this case, the cost of metalworking tools can be up to $50 \%$ of the total cost of machining parts. First of all, this refers to those machining operations where used metalworking tools as broaches, hob cutters, and gear-shaping cutters. These tools are specialized and use to perform the most labor-intensive technological operations, mainly in aircraft engineering when processing the herringbone type

\footnotetext{
* e-mail: a.shein1978@gmail.com
}

joint broaches in the turbine discs for attaching blades to them, when processing the gear-shaping cutters splined connections of turbine rotors with the compressor rotor or gearbox shaft, as well as other responsible operations [1-4]. Despite the rapid spread of precast carbide tools in the industry, high-speed steels are still a significant amount. They are widely used in the manufacture of complex metalworking tools. Developments toward the replacement of the traditional operations of forming geometrically complex surfaces of parts of aircraft engines to alternative processes, for example, advanced electrical discharge machining or additive technologies as layer-by-layer synthesis and others are still at the stage of industrial testing and single production. Thus, the leading role of metalworking tools today is difficult to overestimate.

Requirements for the quality of tools increase when it comes to the manufacture of parts from heat-resistant and hard-to-machine steels and alloys, which are mainly used in the aviation industry due to their high performance. At the same time, along with increased performance, the parts made of these materials are characterized by poor workability, which is associated with their high hardness or strength, low thermal conductivity, and others. In such circumstances, the metalworking tool must have a whole complex of sometimes contradictory physical and mechanical properties as high hardness, durability, heat resistance, low affinity with the processed material, and others.

Today the universal tool materials which could provide high operational indicators of tools at the various characters of conditions of their operation are not created 
yet, and the opportunities of the tool materials used in mechanical engineering are in many respects exhausted. Tool materials specialized for certain working conditions have different physical and mechanical properties. Since the creation of new material is an extremely expensive process, stretching for decades, the use of technologies related to the improvement of the properties of the surface layers of metalworking tools made of traditional materials is actively used around the world. The most widespread among them are the technologies of applying thin vacuumplasma coatings. When it is necessary to apply coatings on a tool made of high-speed steel, the most suitable and universal is the cathode arc deposition process (Arc-PVD process), which has high performance, excellent reproducibility and is implemented at temperatures not exceeding $600{ }^{\circ} \mathrm{C}[5-10]$.

For the tools of high-speed steels, the main effect of the coating is to increase the hardness of the cutting tool contact pads and reduce their adhesive interaction with the processed material. As a result, the functional and physical parameters of the machining process are transformed: chip formation, contact, and thermal processes, as well as wear of the tool work flanks. The consequences of these changes are as follows:

- Firstly, an increase in the dimensional stability of the cutting tool, which leads to more cost-effective use of tool materials;

- Secondly, it is the displacement of the permissible cutting speeds for this tool material in the region of higher values, which provides an increase in processing productivity;

- And thirdly, a decrease in roughness and an increase in the accuracy of the machined parts. The latter is especially important when it comes to finishing machining operations, such as stretching. Another effect that can be achieved by coating is minimizing the amount of used cutting fluid, and, in some cases, eliminating its use, that is implementing environmentally friendly machining technologies [11-16].

Despite all the undeniable advantages of vacuum plasma coatings, in practice, it is often possible to observe their rapid destruction due to plastic deformation of the highspeed base under the influence of complex loads arising during the cutting process. For example, during milling when the tool is subjected to cyclic loads or during stretching when it is difficult to remove chips from the cutting zone and therefore appears increased thermal loads. In some works [17,18], it is shown that in most cases the destruction of the "coating - high-speed base" begins with the plastic deformation of the high-speed base under the coating. Also, due to the large difference in the properties of the hard coating and high-speed steel on the boundary of their contact, high stresses are formed, which contribute to poor adhesion of coatings and rapid destruction. Thus, the load resistance in the system "coating - high-speed base" largely depends on the properties of the substrate. It is clear that the formation of a transition layer on the surface of a high-speed tool, which has high hardness and heat resistance, will increase the tool's resistance to loads. The creation of such a layer followed by the application of a harder coating is one of the options for duplex surface treatment, which has become quite common in engineering. For example, in the works of some authors, before coating the tool of high-speed steel is proposed to form a transition layer by ion implantation or laser treatment. The authors note a significant increase in tool life with duplex treatment compared with coated tools [19-25].

However, the most promising and cost-effective is the technology of duplex surface treatment of cutting tools of high-speed steels when the formation of the transition layer by ion nitriding and subsequent application of the wearresistant coating are performed in a single technological cycle [26-34]. Scientists of MSTU "STANKIN" have repeatedly shown the effectiveness of this approach on the example of turning, milling, and drilling of various structural steels with a tool of high-speed steel type HS6-5-2. For example, the resistance of end mills in the processing of structural steel type $41 \mathrm{Cr} 4$ due to the formation of a nitrided layer before coating ( $\mathrm{Ti}, \mathrm{Al}) \mathrm{N}$ was increased by two times compared with the tool $\mathrm{C}(\mathrm{Ti}, \mathrm{Al}) \mathrm{N}$ and up to five times compared with the uncoated cutters. The effect of increasing the resistance after duplex treatment is especially manifested as the cutting speed increases. Advanced results were obtained when operating experimental samples of nitrided high-speed tools with a coating (Nb-Ti-Al-V) N [35-39].

Naturally, the specific operating conditions of the tool require the creation of a coated nitrided layer with the development of specific structural components, a certain thickness and microhardness, which ultimately will determine the performance of the tool in the cutting process. The method of production as casting or powder metallurgy and the composition of high-speed steel, which is subjected to duplex treatment, is critical. The optimal composition of the nitrided layer for different high-speed can be very different [40-45].

The role of the nitrided layer is crucial in duplex vacuum plasma treatment of metalworking tools since this layer is responsible for the strength of the adhesive bond between the coating and high-speed steel. It is the fundamental basis for the successful operation of the coating and the tool as a whole in the process of operation.

Within the limits of this work, there were investigated some of the most complex processes of shaping, common in aircraft engineering:

- Treatment of herringbone type joint by broaches of highspeed steel in turbine discs of heat-resistant alloys, to which the blades are attached (Fig. 1a);

- Treatment of involute non-through splines in the inner hole of parts of the "bushing" type of heat-resistant alloy (Fig. 1b), which are used to connect various turbine parts, by gear-shaping cutters of high-speed steel.

The purpose of this work was the experimental study of the duplex vacuum-plasma treatment effect, including sequential ion nitriding under various conditions and applying a composite coating $(\mathrm{Nb}-\mathrm{Ti}-\mathrm{Al}-\mathrm{V}) \mathrm{N}$ on the characteristics of the surface layer and the wear rate of herringbone broaches and gear-shaping cutters made of powder highspeed steels in the processing of heat-resistant nickel alloy. 


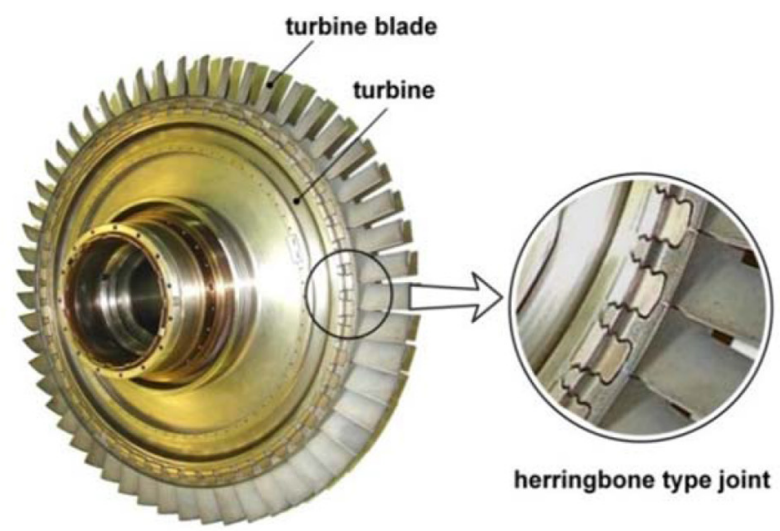

(a)

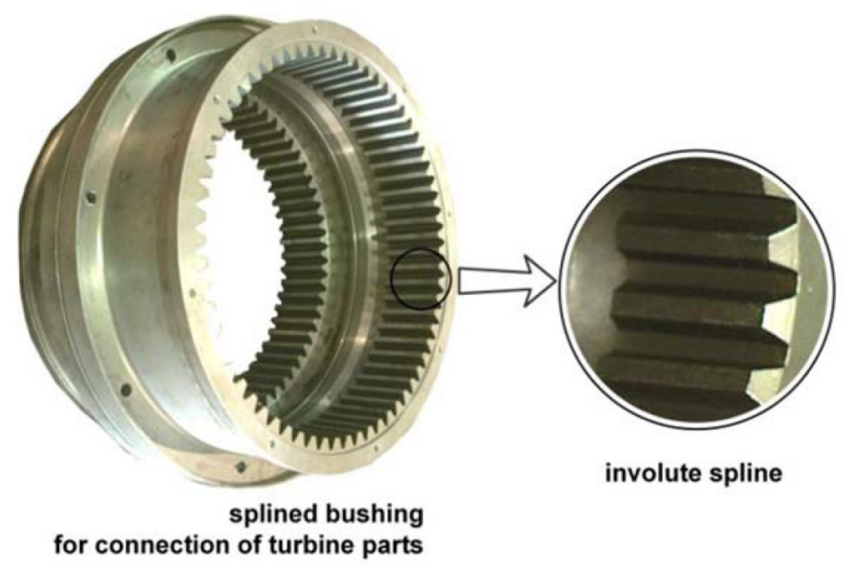

(b)

Fig. 1. Complex profile surfaces of critical parts of aircraft engines, which were the subject of research of this work: (a) herringbone type joint in turbine disks of heat-resistant alloy; (b) involute non-through splines in the inner hole of the "bushing" type part of the heat-resistant alloy.

At the same time, the cutting tool and its operating conditions were as close as possible to the real production ones. In the final part of the research, the authors solved the problem of quantitative assessment of the effect of the proposed duplex machining on the durability of complex profile tools from high-speed steels.

The scientific novelty of the work is in the nitriding and coating of the cutting tools simultaneously during one technological cycle in the developed vacuum chamber, which reduces the main and auxiliary process timing and excludes the necessity of multiple rebasing of tools. It can have a positive influence on operational properties of the treated cutting tools and, as a consequence, on accuracy characteristics of the machined parts. The developed technology of duplex vacuum-plasma treatment has no analog in the modern industry. In addition, the work was performed for two types of cutting tools with the sophisticated and splined geometrical working profile as broaches for herringbone type joints and gear-shaping cutters from high-speed steels by powder metallurgy. The rational modes were defined for each of the tool types according to the data of the experiments in the conditions of the real production. There are plenty of the researches related to more traditional tool material as HS6-5-2 by DIN, but there are almost no experimental data for the promising materials produced by advanced technologies with better performance properties as materials presented in the current work.

The practical significance of the work in the development of the technology and machine for duplex technology, which increases the dimensional stability of the cutting tool, increase the productivity of processing due to the possibility of using higher rational cutting modes, decrease the final roughness, and increase the accuracy of the machined parts. It should be noted that nitriding usually produces in a glow discharge when in the current work it is performed in a vacuum arc discharge, and the obtained layers are even thicker than for nitriding in a glow discharge.

\section{Materials, original technological equipment, experimental, and instrument base}

\subsection{Cutting tools and work material}

Two types of cutting tools were used in experimental studies:

- Broaches for herringbone type joints with the number of the teeth $z=27-34$, the front angle $\gamma=6^{\circ}-8^{\circ}$ and a back angle $\alpha=3^{\circ}-5^{\circ}$ (Fig. 2a).

- Gear-shaping cutters with diameter $d=80 \mathrm{~mm}$, module $m=2$, the number of the teeth $z=38$ and back angle $\alpha=20^{\circ}$ (Fig. 2b).

The elemental composition of high-speed steels, from which the tools were made, is given in Table 1.

A heat-resistant nickel-based alloy, which is widespread in the aviation industry, was used as a material to be processed for the operational tests. The elemental composition of the alloy is shown in Table 2 .

\subsection{Technological equipment and process of duplex vacuum-plasma treatment of tools}

Immediately before loading the tool into the vacuum plasma unit chamber, ultrasonic complex cleaning was carried out at a temperature of $600{ }^{\circ} \mathrm{C}$ in an aqueous solution of alkalis for $10 \mathrm{~min}$ to remove fat and oil contamination from the surface of the samples. Then the samples were washed in particular solutions and dried at a temperature of $1500^{\circ} \mathrm{C}$ to remove moisture from the surface and effectively prevent oxidation.

Duplex vacuum-plasma treatment of high-speed tools was carried out in a multifunctional automated technological unit. A general view of the unit is shown in Figure $3 \mathrm{a}$ and its fundamental internal structure is shown in Figure 3b. The equipment is based on the classic Arc-PVD process, while it is originally structurally 


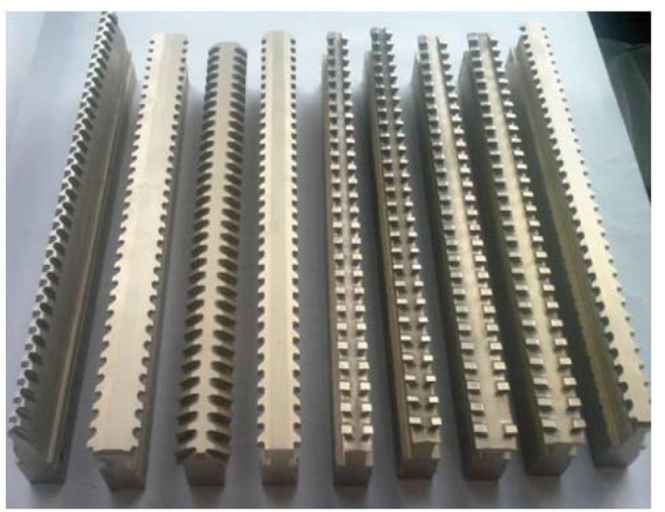

(a)

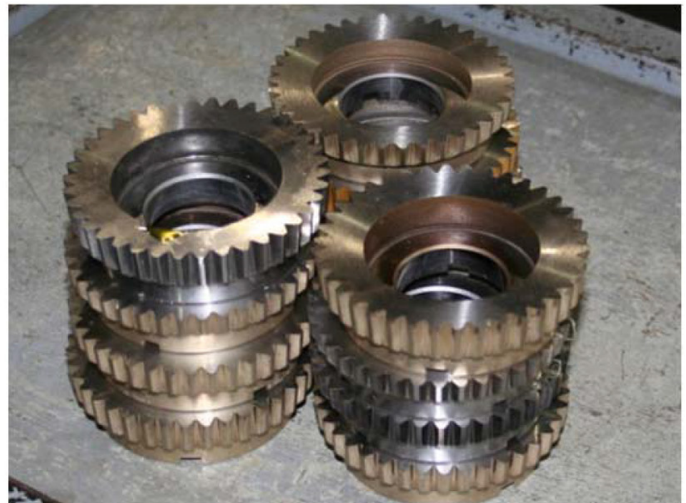

(b)

Fig. 2. Design of cutting tools for experimental studies: (a) a set of broaches for treatment of herringbone type joint; (b) a set of gear-shaping cutters.

Table 1. The chemical composition of high-speed steels used in experiments.

\begin{tabular}{lllllllllll}
\hline Cutting tool & \multicolumn{8}{c}{ The elemental composition of the cutting tool material, \% of the mass } \\
\cline { 2 - 10 } & $\mathrm{Fe}$ & $\mathrm{C}$ & $\mathrm{Cr}$ & $\mathrm{Mo}$ & $\mathrm{W}$ & $\mathrm{V}$ & $\mathrm{Co}$ & $\mathrm{Si}, \mathrm{Mn}, \mathrm{Ni}, \mathrm{S}, \mathrm{P}$ & Remark \\
\hline Broach for herringbone type joint & Base & 2.5 & 4.0 & 3.0 & 12.0 & 6.5 & 5.0 & No more than 1.6 & Powder metallurgy \\
Gear-shaping cutter & Base & 1.1 & 4.0 & 7.0 & 6.5 & 2.5 & 10.5 & No more than 1.6 & Powder metallurgy \\
\hline
\end{tabular}

Table 2. The chemical composition of the nickel-based heat-resistant alloy (material to be processed).

\begin{tabular}{lllllll}
\hline \multicolumn{7}{c}{ The elemental composition of the part material, \% of the mass } \\
\hline $\mathrm{Ni}$ & $\mathrm{C}$ & $\mathrm{Cr}$ & $\mathrm{Co}$ & $\mathrm{Mo}$ & $\mathrm{Al}$ & $\mathrm{Ti}$ \\
Base & 0.066 & 10.0 & 16.5 & 3.5 & 5.0 & 2.0 \\
& & & & & \\
$\mathrm{~W}$ & $\mathrm{Nb}$ & $\mathrm{Hf}$ & $\mathrm{Si}$ & $\mathrm{Mn}$ & $\mathrm{Fe}$ & Other elements \\
5.5 & 2.5 & 0.4 & 0.5 & 0.5 & 0.5 & No more than 11.5 \\
\hline
\end{tabular}

executed and differs from similar equipment. All stages of the technological process of duplex machining high-speed tools occur sequentially in a vacuum chamber. The equipment contains a target that acts as a cathode evaporating by the cathode spots of a vacuum arc [46-48]. The design of the machine provides four vacuum arc evaporators with electrodes arranged staggered on the walls of the vacuum chamber to ensure uniform deposition of the coating on the tool samples.

One of the electrodes must operate in the anode mode and be installed opposite one of the cathodes. Between the cathode and the anode, original devices in the form of butterfly valves are installed. They conditionally divide the vacuum chamber into two parts. On the left side from the butterfly valves, the chamber is filled with a plasma consisting of metal particles and gas. On the right side, the chamber is filled with gas plasma. Butterfly valves do not let the micro-drops, neutral atoms, and metal ions emitted by cathode spots on the surface of the target pass. Only electrons penetrate through butterfly valves, ionize the gas supplied to the vacuum chamber on the way to the anode. A gas plasma that does not contain formed metal particles due to this technical solution.

The cutting tool placed on the planetary rotation device was heated by electrons when a positive potential was applied to it. It was an essential step since, in the case of insufficient heating, a low-quality coating is formed. When a negative potential was applied to the cutting tool and neutral gas as argon or helium was supplied to the chamber, ion etching of the tool surface was carried out. In the case when the reaction gas as nitrogen was supplied to the chamber, nitriding by gas ions occurred.

When the butterfly valves rotated, the metal particles from which the targets were made accelerated to the tool surface, interacted with it, and in the presence of the reaction gas, the nitride coating was deposited. 


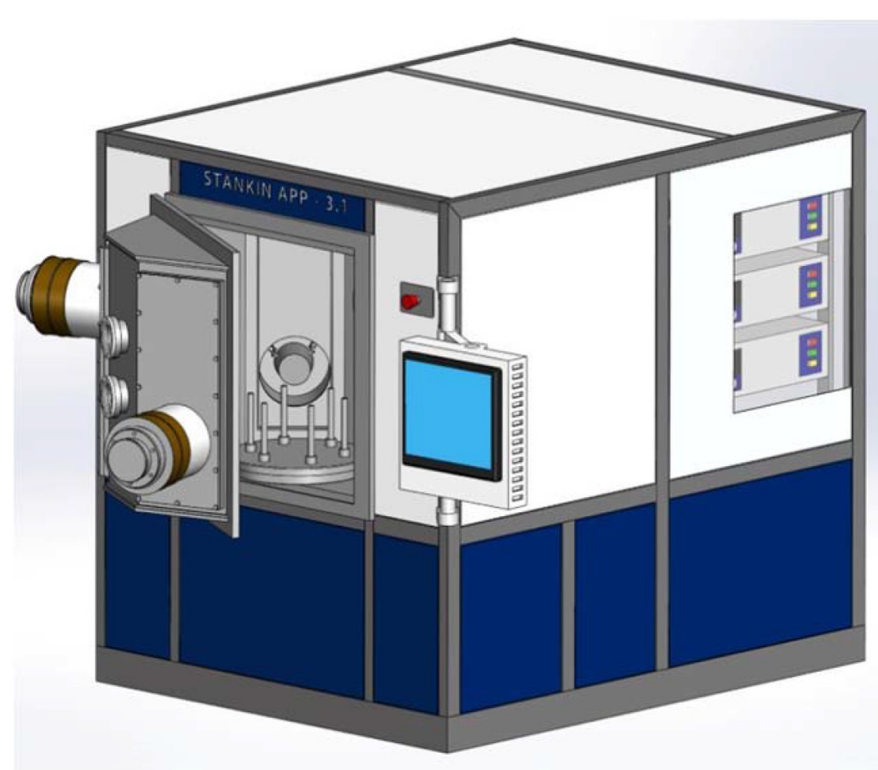

(a)

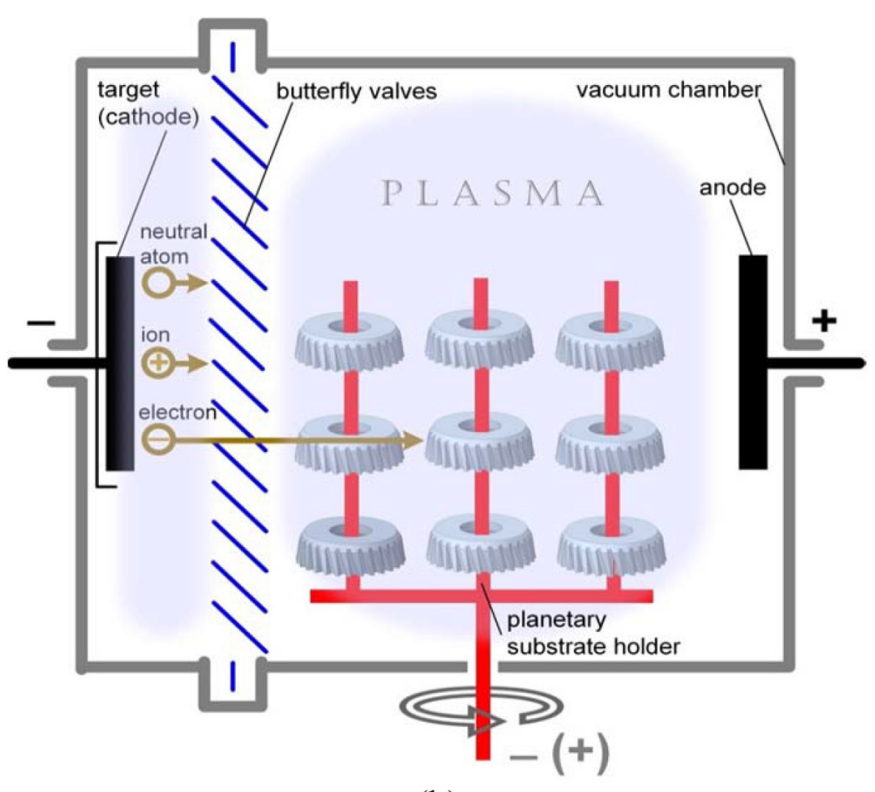

(b)

Fig. 3. Technological unit for duplex machining of high-speed tools: (a) general view; (b) schematic diagram.

The high-speed tool in the process of duplex treatment was placed on the planetary substrate holder and during the entire technological cycle performed the planetary rotation.

Summarizing the above principles, the technological process of duplex treatment using the equipment described above included the following steps:

- Heating of high-speed tools by electrons;

- Etching of the surface layer with ions of argon or helium;

- Nitriding of the surface layer with nitrogen ions;

- Formation of the wear-resistant coating $(\mathrm{Nb}-\mathrm{Ti}-\mathrm{Al}-\mathrm{V}) \mathrm{N}$.
Analysis of the results of studies that were previously obtained by the authors and some scientists involved in duplex treatment allows making an important conclusion. During nitriding of high-speed steels with nitrogen ions, the composition of the gaseous medium has a priority effect on the structure of the nitrided layer, in particular on the formation of $\varepsilon, \gamma^{\prime}$, and $\alpha$-phases. The holding time and the temperature of the process have a priority effect on the thickness and microhardness of the layer formed during nitriding with nitrogen ions. Table 3 provides information on the modes of nitriding with nitrogen ions, which have been comprehensively studied in this work.

It should be noted that the pressure of the gas medium during the nitriding experiments was constant and maintained at $0.5 \mathrm{~Pa}$. It is because the pressure range at which there is a stable vacuum arc discharge is relatively narrow, and this parameter has been well studied by the authors in previous works.

During the experiments, we deliberately did not study the process of formation of the nitrided layer in the medium of $100 \%$ and $80 \%$ nitrogen, since it was previously established that in this case a continuous layer consisting of a highly solid and simultaneously fragile $\varepsilon$-phase $\left(\mathrm{Fe}_{2} \mathrm{~N}\right)$ up to $5 \mu \mathrm{m}$ thick is formed on the surface. The formation of this phase minimizes the effect of duplex treatment of highspeed tools, as the coating applied to a very fragile surface layer has poor adhesion. The authors obtained these results for steel HS6-5-2. However, it is evident that for previously unexplored steels, which are the subject of this work, these conclusions will be valid.

When coating the nitrided samples in the vacuum chamber of the unit, four cathodes were provided: three alloy composite cathodes (Nb-Ti-Al-V) and one cathode made of titanium, which was used as a source of electrons. The chemical composition of composite cathodes by weight was: $\mathrm{Nb}-55 \%, \mathrm{Ti}-32 \%, \mathrm{Al}-8 \%$, and $\mathrm{V}-5 \%$. During coating, the modes were preliminarily optimized by the authors and were constant during all experiments. Table 4 summarizes some experimental data. Based on the evaluation of the adhesion of coatings applied under different conditions, their microhardness and other standard indicators were chosen: a rational bias voltage of $220 \mathrm{~V}$; rational arc current at the cathode $(\mathrm{Nb}-\mathrm{Ti}-\mathrm{Al}-\mathrm{V})$ of $70 \mathrm{~A}$, at the titanium cathode of $80 \mathrm{~A}$; and rational pressure in the vacuum chamber of $0.45 \mathrm{~Pa}$. Under these conditions, the temperature of the coating process was $450{ }^{\circ} \mathrm{C}-470^{\circ} \mathrm{C}$, and the ion current density was $0.5 \mathrm{~A} / \mathrm{mm}^{2}$.

\subsection{Metallographic and physical studies}

Preparation of metallographic sections of samples of highspeed steels was carried out on the equipment of Struers ApS (Copenhagen, Denmark). For this purpose were used a cutting machine, an automatic hydraulic press, devices for polishing, and grinding for microsections. Particular samples of $20 \times 20 \mathrm{~mm}$ square shape were made for research.

The manufacture of thin sections intended for metallographic studies was carried out according to the standard method - samples were poured with acrylic plastic in metal form, after which the allowance was removed to the desired section on a surface grinding machine with sufficient 
Table 3. Nitriding modes of high-speed steels by nitrogen ions.

\begin{tabular}{|c|c|c|c|}
\hline$\frac{\text { Nitriding mode }}{\text { The composition of the gas environment (nitrogen/argon) ( } \% \text { at.) }}$ & \multicolumn{3}{|c|}{ Ranges of variation and mode values } \\
\hline Holding time during nitriding, min & 30 & 45 & 60 \\
\hline
\end{tabular}

Table 4. Coating modes of (Nb-Ti-Al-V) $\mathrm{N}$ on high-speed steels.

\begin{tabular}{|c|c|c|c|c|c|c|}
\hline \multirow{2}{*}{$\begin{array}{l}\text { No. of } \\
\text { experiment }\end{array}$} & \multicolumn{4}{|c|}{ Process parameters } & \multicolumn{2}{|c|}{ Coating characteristics } \\
\hline & $\begin{array}{l}\text { Arc current } \\
(\mathrm{Nb}-\mathrm{Ti}-\mathrm{Al}-\mathrm{V})(\mathrm{A})\end{array}$ & $\begin{array}{l}\text { Bias } \\
\text { voltage }(\mathrm{V})\end{array}$ & $\begin{array}{l}\text { Nitrogen } \\
\text { pressure }(\mathrm{Pa})\end{array}$ & $\begin{array}{l}\text { Duration of } \\
\text { the process }(\mathrm{min})\end{array}$ & $\begin{array}{l}\text { Microhardness } \\
(\mathrm{Gpa})\end{array}$ & $\begin{array}{l}\text { Thickness } \\
(\mu \mathrm{m})\end{array}$ \\
\hline 1 & 70 & 220 & 0.25 & 60 & 20.5 & $4.3-4.5$ \\
\hline 2 & 70 & 220 & 0.35 & 60 & 23.0 & $4.3-4.5$ \\
\hline 3 & 70 & 220 & 0.45 & 60 & 27.5 & $4.2-4.3$ \\
\hline 5 & 80 & 210 & 0.35 & 60 & 22.5 & $4.4-4.7$ \\
\hline 6 & 80 & 210 & 0.45 & 60 & 25.9 & $4.4-4.7$ \\
\hline 7 & 90 & 210 & 0.25 & 60 & 21.0 & $4.5-4.8$ \\
\hline 8 & 90 & 200 & 0.35 & 60 & 20.6 & $4.5-4.8$ \\
\hline 9 & 90 & 200 & 0.45 & 60 & 24.0 & $4.4-4.8$ \\
\hline
\end{tabular}

cooling. The polishing of the samples was carried out using diamond paste with a grain size of $2 / 1$ and $1 / 100$, applied on thick paper.

The study of the structure and determination of the thickness of the nitrided layer was carried out by chemical etching with a solution of ferric chloride in ethyl alcohol with the addition of hydrochloric acid. For preventing distortion of the studied structures during etching, the etched sections were washed by free immersion in ethyl alcohol with subsequent air-drying. Measurement of microhardness, structure photographing, as well as measurement of the thickness of the nitrided layer and coatings were carried out on the transverse microsections on the device Polyvar Met (AO Reichert, Vienna, Austria). The distribution of chemical elements on the surface of samples with duplex treatment was studied using a scanning electron microscope Vega3 LMH (Tescan, Brno, The Czech Republic).

X-ray diffraction analysis of the nitrided layer was performed on an Empyrean PANalytical automated diffractometer (Malvern Panalytical Ltd, Malvern, UK). A survey of nitrided samples was carried out using $\mathrm{CuK} \alpha$ radiation. Obtaining information on the phase composition of the ultrafine nitrided surface layer of the order of $5-8 \mu \mathrm{m}$, required a survey, applied when the angle of incidence of the $\mathrm{X}$-ray beam relative to the surface under study was about $5^{\circ}$ as it calls examination in sliding geometry.

\subsection{Performance testing of cutting tools}

\subsubsection{Stretching of herringbone type joint}

The tests of broaches were carried out on verticalbroaching machine Kurt Hoffmann (Hoffmann Räumtechnik GmbH, Pforzheim, Germany) with a hydraulic drive RASX 25 when processing herringbone type joint in the turbine disc of the heat-resistant alloy. The wear on the rear surface was taken for the criterion of failure or loss of the working condition of the broaches. The maximum value of the criterion was defined as $200 \mu \mathrm{m}$. As shown by earlier studies, after reaching this value, the quality of the surface layer deteriorates significantly. Deterioration in the quality of the processed spline can lead to the loss of an expensive turbine disc.

Preliminary and final profile broaches were tested at a cutting speed of $3 \mathrm{~m} / \mathrm{min}$. Pre-slitting broaches worked with the rise of $S_{z}=0.07 \mathrm{~mm}$ per tooth, and the final profile with a feed per tooth of $0.015-0.02 \mathrm{~mm} /$ tooth.

\subsubsection{Slotting blind splines}

The gear-shaping cutter tests were conducted on a gearshaping machine Liebherr (Liebherr GmbH, BiberachRiss, Germany) by slotting blind splines to a depth of $75 \mathrm{~mm}$. The criterion of blunting of the gear-shaping cutter was tool wear on the rear surface. Traditionally, the value of the wear criterion is determined depending on the cutter module and the type of treatment (rough or finish). In the present work, the criterion of failure (loss of working condition) of gear-shaping cutters was taken the wear on the rear surface, the maximum value of which is $300 \mu \mathrm{m}$.

The tests of gear-shaping cutters were carried out at the following modes: the depth of cut was $0.75 \mathrm{~mm}$; the number of double strokes of the cutter per minute was $30 \mathrm{~min}^{-1}$; the radial feed was $0.03 \mathrm{~mm} /$ double-stroke; and the circular feed was $0.121 \mathrm{~mm} /$ double-stroke. The water-based emulsion was used as a lubricant-cooling medium. 
Table 5. The effect of temperature and composition of the gas medium on the thickness and microhardness of the nitrided layer of high-speed steel of the broaches for herringbone type joint at holding time for nitriding with nitrogen ions of $45 \mathrm{~min}$.

\begin{tabular}{|c|c|c|c|c|}
\hline \multicolumn{2}{|r|}{ Nitriding mode } & \multicolumn{2}{|c|}{ The thickness of the nitrided layer } & \multirow{2}{*}{$\begin{array}{l}\text { Maximum } \\
\text { microhardness }(\mathrm{GPa})\end{array}$} \\
\hline $\begin{array}{l}\text { Process } \\
\text { temperature }\end{array}$ & $\begin{array}{l}\text { The ratio of gases } \\
\text { during nitriding (nitrogen/argon) }\end{array}$ & $\begin{array}{l}\text { Productive } \\
\text { thickness }(\mu \mathrm{m})\end{array}$ & $\begin{array}{l}\text { Total } \\
\text { thickness }(\mu \mathrm{m})\end{array}$ & \\
\hline \multirow[t]{3}{*}{$450^{\circ} \mathrm{C}$} & $20 \% \mathrm{~N}_{2} / 80 \% \mathrm{Ar}$ & 40 & $140-150$ & 11.2 \\
\hline & $40 \% \mathrm{~N}_{2} / 60 \% \mathrm{Ar}$ & $25-30$ & 100 & 11.8 \\
\hline & $60 \% \mathrm{~N}_{2} / 40 \% \mathrm{Ar}$ & $10-15$ & $70-80$ & 12.2 \\
\hline \multirow[t]{3}{*}{$480^{\circ} \mathrm{C}$} & $20 \% \mathrm{~N}_{2} / 80 \% \mathrm{Ar}$ & 55 & $175-190$ & 12.0 \\
\hline & $40 \% \mathrm{~N}_{2} / 60 \% \mathrm{Ar}$ & $30-40$ & $140-150$ & 12.6 \\
\hline & $60 \% \mathrm{~N}_{2} / 40 \% \mathrm{Ar}$ & 20 & $110-120$ & 13.1 \\
\hline \multirow[t]{3}{*}{$510^{\circ} \mathrm{C}$} & $20 \% \mathrm{~N}_{2} / 80 \% \mathrm{Ar}$ & 85 & $300-320$ & 12.9 \\
\hline & $40 \% \mathrm{~N}_{2} / 60 \% \mathrm{Ar}$ & $60-70$ & $250-270$ & 13.5 \\
\hline & $60 \% \mathrm{~N}_{2} / 40 \% \mathrm{Ar}$ & 50 & 180 & 14.0 \\
\hline
\end{tabular}

\section{Results of experimental studies}

\subsection{Effect of nitriding on the characteristics of the surface layer of high-speed steels}

In the study of the surface properties of the high-speed tool after nitriding with nitrogen ions, the authors divided the nitrided layer thickness into two components following generally accepted classification:

- Productive thickness is the thickness of the layer with the maximum microhardness, which is the distance from the surface of the sample to the area with a hardness corresponding to the value of $11.0 \mathrm{GPa}$.

- Total thickness is the thickness of the layer, which is the distance from the surface of the sample to the area with a hardness corresponding to the initial hardness of highspeed steel. For high-speed steels, of which complexprofile tools were made, the initial hardness on the surface was $10 \mathrm{GPa}$ for bounds and $9.8 \mathrm{GPa}$ for gearshaping cutters.

\subsubsection{Characteristics of the surface layer of broaches after nitriding}

Table 5 presents the experimental data on the effect of temperature and composition of the gas medium on the thickness and microhardness of the nitrided layer of highspeed steel. It is seen that the increase in the percentage of argon in nitrogen-argon gas media significantly increases the surface hardness, but it leads to some decrease in the maximum surface hardness. Conversely, with an increase in the percentage of nitrogen, there is a decrease in the thickness of the layer formed during nitriding: both the productive and the total thickness decreases. At the same time, the hardness of the surface layer increases. For example, when nitriding at a temperature of $450{ }^{\circ} \mathrm{C}$ and the holding time of $45 \mathrm{~min}$, an increase in the percentage of nitrogen from $20 \%$ to $60 \%$ leads to a decrease in the

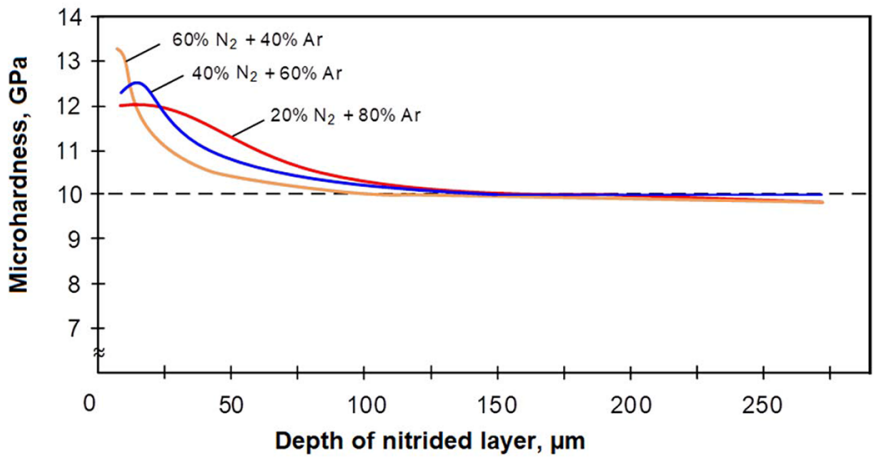

Fig. 4. The surface nitrided layer microhardness distribution for high-speed steel of the broaches for herringbone type joint at holding time for nitriding with nitrogen ions of $45 \mathrm{~min}$.

productive thickness from 40 to $10-15 \mu \mathrm{m}$, and the total thickness from $140-150$ to $70-80 \mu \mathrm{m}$. In this case, the hardness increases from 11.2 to $12.2 \mathrm{GPa}$. This trend persists over the entire range of the investigated temperatures of the nitriding process. As for the process temperature and its influence on the characteristics of the nitride layer, an increase in temperature by $60^{\circ} \mathrm{C}$ (from 450 to $510^{\circ} \mathrm{C}$ ) increases the productive and total thickness of the nitrided layer up to two times was detected (Tab. 5). The surface hardness is increased by $1.5 \mathrm{GPa}$. Further increase in temperature is dangerous, as it can cause the tempering of thin surface layers of high-speed steel.

It may seem that the increase in hardness by $1-1.5 \mathrm{GPa}$ is insignificant. However, for high-speed steels, $1 \mathrm{GPa}$ is about $10 \%$ of the initial hardness.

Figure 4 shows the characteristic curves of the hardness distribution over the depth of the nitrided layer of highspeed steel, from which the broach for herringbone type joint was made. The presented dependencies are typical for diffusion processes. On the surface of the samples the hardness is maximum, and then gradually decreases to the hardness of the original high-speed steel. 
Table 6. The effect of the holding time during nitriding on the layer thickness and the maximum microhardness of surface layer of high-speed steel of broaches for herringbone type joint at process temperature of $480^{\circ} \mathrm{C}$ and gas ratio of $40 \% \mathrm{~N}_{2}+60 \%$ Ar.

\begin{tabular}{llll}
\hline $\begin{array}{l}\text { Holding time at } \\
\text { nitriding, min. }\end{array}$ & $\begin{array}{l}\text { Productive thickness } \\
(\mu \mathrm{m})\end{array}$ & $\begin{array}{l}\text { Total thickness } \\
(\mu \mathrm{m})\end{array}$ & $\begin{array}{l}\text { Maximum microhardness } \\
(\mathrm{GPa})\end{array}$ \\
\hline 30 & 25 & 100 & 12.0 \\
45 & $30-40$ & $140-150$ & 12.6 \\
60 & 50 & $280-300$ & 12.9 \\
\hline
\end{tabular}

Table 7. X-ray structural analysis of the phase composition of the surface layer of high-speed steel of the broaches for herringbone type joint after nitriding with different gas ratios, at nitriding temperature of $480^{\circ} \mathrm{C}$ and holding time of $45 \mathrm{~min}$.

\begin{tabular}{llll}
\hline Phase composition & \multicolumn{2}{c}{ Volume fraction of phase (\%) in nitrided layer } \\
\cline { 2 - 4 } & $20 \% \mathrm{~N}_{2}+80 \% \mathrm{Ar}$ & $40 \% \mathrm{~N}_{2}+60 \% \mathrm{Ar}$ & $60 \% \mathrm{~N}_{2}+40 \% \mathrm{Ar}$ \\
\hline Radiation used: CuKa (shooting in sliding geometry) & & 24.6 \\
$\mathrm{Fe}_{2} \mathrm{~N}$ & - & 14.2 & 10.5 \\
$\mathrm{Mo}_{2} \mathrm{~N}$ & 15.8 & 29.3 & 21.4 \\
$\mathrm{Fe}_{3}(\mathrm{~W}, \mathrm{Mo})_{3}(\mathrm{C}, \mathrm{N})$ & 36.0 & 56.5 & 43.5 \\
$\mathrm{Fe} \alpha(\mathrm{C}, \mathrm{N})$ & 48.2 & & \\
$\mathrm{Radiation}_{\mathrm{Fe}} \mathrm{N}$ used: CuKa & & - & 6.4 \\
$\mathrm{Fe}_{2} \mathrm{~N}$ & - & 2.9 & 3.9 \\
$\mathrm{Mo}_{2} \mathrm{~N}$ & 1.7 & 6.6 & 8.0 \\
$\mathrm{Fe}_{3}(\mathrm{~W}, \mathrm{Mo})_{3}(\mathrm{C}, \mathrm{N})$ & 6.1 & 90.5 & 81.7 \\
$\mathrm{Fe} \alpha(\mathrm{C}, \mathrm{N})$ & 92.2 & &
\end{tabular}

The effect of the holding time on the thickness and maximum microhardness of the surface layer of high-speed steel during nitriding is shown in Table 6 . Increasing the nitriding time twice (from 30 to $60 \mathrm{~min}$ ) leads to a two-fold increase in thickness, while the microhardness increases by less than $1 \mathrm{GPa}$. As shown by earlier studies, an increase in the holding time of more than $60 \mathrm{~min}$ is impractical, since the main processes of diffusion saturation of high-speed steels occur in this particular time range and are further slowed down. Also, a further increase in the holding time can lead to an increase in the radius of the cutting edge due to excessive etching.

Table 7 presents the data of X-ray diffraction analysis of the surface layer. It can be seen that in the surface layer of samples nitrided in a medium containing $60 \%$ nitrogen there is an $\varepsilon$-phase. It is not firm, because when shooting in sliding geometry (at a depth of $5-8 \mu \mathrm{m}$ ) the $\mathrm{Fe}_{2} \mathrm{~N}$ phase is about $25 \%$. The remaining phase components that were detected on the diffractometer are $\mathrm{Mo}_{2} \mathrm{~N}, \mathrm{Fe}_{3}(\mathrm{~W}, \mathrm{Mo})_{3}(\mathrm{C}, \mathrm{N})$, and $\mathrm{Fe} \alpha(\mathrm{C}, \mathrm{N})$. Further reduction of nitrogen in the gas environment blocks the formation of highly undesirable nitrides $\mathrm{Fe}_{2} \mathrm{~N}$ and increases the amount of $\mathrm{Fe} \alpha(\mathrm{C}, \mathrm{N})$ solid nitrogen solution in martensite. For example, at a gas ratio of $20 \% \mathrm{~N}_{2} / 80 \% \mathrm{Ar}$, the percentage of this phase in the surface layer exceeds $90 \%$.

The patterns described above and the data of X-ray structural analysis are in good agreement with the optical photographs of the microstructure of nitrided samples shown in Figure 5. The dark etched layer approximately corresponds to the productive thickness of the nitrided layer. The wide transition zone that follows the dark zone (total thickness of the nitrided layer), where the hardness remains increased due to the presence of nitrogen in the $\alpha$-solid solution, is etched almost the same as the nonnitrided high-speed substrate, but visually there are specific differences.

\subsubsection{Characteristics of the surface layer of gear-shaping cutters after nitriding}

Because of nitrogen diffusion, chemical compounds with iron and alloying elements are formed in the surface layer of tool steels. It is evident that the chemical composition of the steel influences the course of diffusion processes of saturation of the surface layer of the tool with nitrogen ions. At the same time, as practice shows, the mechanism of diffusion processes of nitriding for all high-speed steels is almost the same, but the characteristics of the formed layers during nitriding for different steels are significantly different.

There is no need to repeat the description of the patterns already given above for the high-speed steel of the broaches. For the gear-shaping cutter tool material, similar patterns are maintained related to the effect of nitriding modes (process temperature, holding time, and nitrogen content in the gas medium) on the productive and total thickness of the 


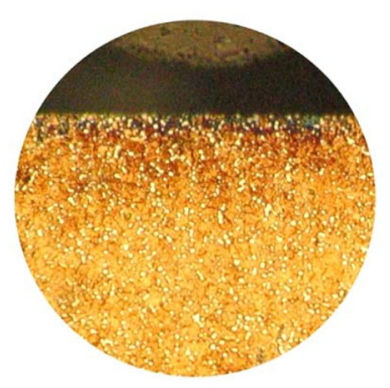

(a)

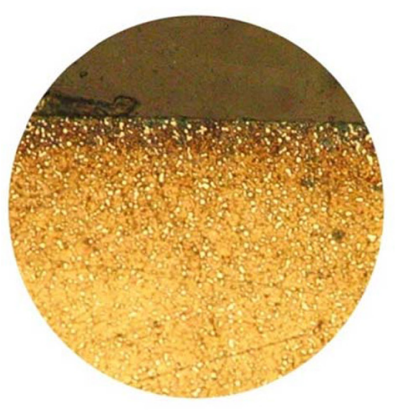

(c)

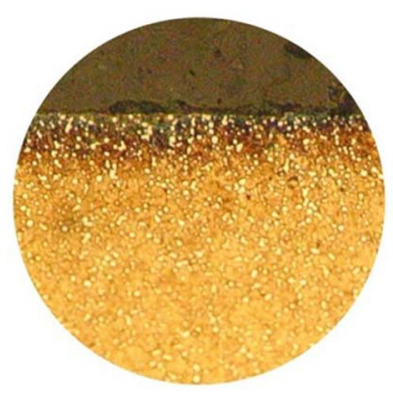

(b)

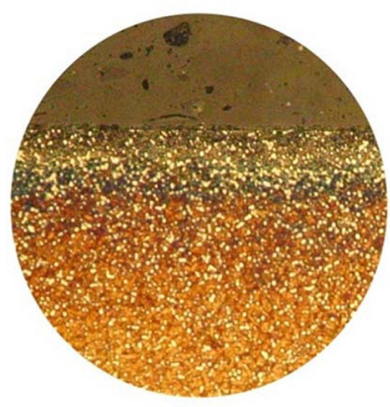

(d)

Fig. 5. Microstructures $(\times 750)$ of the nitrided high-speed steel surface layer of the broach for herringbone type joint: (a) $20 \% \mathrm{~N}_{2} / 80 \%$ Ar, $450{ }^{\circ} \mathrm{C}, 30 \mathrm{~min}$; (b) $40 \% \mathrm{~N}_{2} / 60 \% \mathrm{Ar}, 510^{\circ} \mathrm{C}, 45 \mathrm{~min}$; (c) $60 \% \mathrm{~N}_{2} / 40 \% \mathrm{Ar}, 480{ }^{\circ} \mathrm{C}, 45 \mathrm{~min}$; (d) $20 \% \mathrm{~N}_{2} / 80 \% \mathrm{Ar}, 510{ }^{\circ} \mathrm{C}, 60 \mathrm{~min}$.

nitrided layer, as well as its microhardness (Tabs. 8 and 9). The character of the microhardness distribution curves over the depth of the nitrided layer of two different types of highspeed steel is almost identical (Figs. 4 and 6). However, with obvious similarities, there are very significant differences, the main of which are the following:

- When nitriding the tool material of gear-shaping cutters in all cases, the thickness of the formed layers (both productive and total) was $20 \%$ higher than the corresponding thickness, which, under identical nitriding modes, were formed in the surface layer of the tool steel from which the broaches were made. The maximum hardness of the surface layer of gear-shaping cutters material in all cases was slightly lower, by $0.2-0.9 \mathrm{GPa}$;

- X-ray structure analysis under angular radiation of nitrided tool material of gear-shaping cutters (Tab. 10) showed that the $\mathrm{Fe}_{2} \mathrm{~N}$ phase ( $\varepsilon$-phase) is present in the surface layer of the samples after nitriding in gas medium containing $60 \%$ and $40 \%$ of nitrogen. Sensitive shooting in sliding geometry allowed establishing that in the first case the amount of phase $\mathrm{Fe}_{2} \mathrm{~N}$ is about $20 \%$, and in the second is $7.5 \%$. In the case of nitriding in $60 \% \mathrm{~N}_{2}+40 \%$ $\mathrm{Ar}$ medium, the $\mathrm{Fe}_{2} \mathrm{~N}$ phase is detected (in an amount of $4 \%$ ) even with standard $\mathrm{CuK} \alpha$ radiation photography. It is important to emphasize that unlike nitriding in pure nitrogen, in this case, the fragile high-nitrogen phase $\mathrm{Fe}_{2} \mathrm{~N}$ is not a continuous layer, which significantly reduces the negatory effect of its formation.

Figure 7 shows the optical images of microstructures of samples of the tool material of gear-shaping cutters nitrided in various modes; the pictures were made in a particular backlight mode for better visualization. Crossmicrosections allow visualization of the patterns described above, and they are in accordance with the X-ray analysis data of nitrided samples. The dark blue area in the photographs approximately corresponds to the thickness of the productive layer, and the transition boundary of the purple to yellow area conventionally corresponds to the total thickness of the nitrided layer.

\subsection{The influence of the coating process on the characteristics of the pre-nitrided surface layer of high-speed steels}

When developing and researching the technology of duplex treatment of high-speed steels, it is important to keep in mind that the nitrided surface layer is subjected to additional thermal effects during the deposition process of the coating. The Arc-PVD process is quite energy intensive. The coating is accompanied by exposure to a plasma stream consisting of high-energy particles, especially at the time of ion bombardment of the nitrided surface. Because of the ongoing processes, the characteristics of the layer obtained by nitriding can be significantly transformed. Therefore, this circumstance must be taken into account when choosing rational modes of the nitrided layer in duplex treatment.

Table 11 shows the experimental data on the effect of the coating process of $(\mathrm{Nb}-\mathrm{Ti}-\mathrm{Al}-\mathrm{V}) \mathrm{N}$ on the characteristics of nitrided high-speed steel, from which the broaches were made. The data demonstrate the validity of the above. A noticeable increase in the total thickness of the nitrided layer is observed in the entire range of modes of formation 
Table 8. The effect of temperature and composition of the gas medium on the thickness and microhardness of the nitrided layer of high-speed steel of the gear-shaping cutters at holding time when nitriding with nitrogen ions of 45 min.

\begin{tabular}{llllll}
\hline & Nitriding mode & & \multicolumn{2}{c}{ Nitrided layer thickness } & $\begin{array}{l}\text { Maximum } \\
\text { microhardness (GPa) }\end{array}$ \\
\cline { 1 - 2 } $\begin{array}{l}\text { Process } \\
\text { temperature }\end{array}$ & $\begin{array}{l}\text { The ratio of gases when } \\
\text { nitriding (nitrogen/argon })\end{array}$ & & $\begin{array}{l}\text { Productive thickness } \\
(\mu \mathrm{m})\end{array}$ & $\begin{array}{l}\text { Total thickness } \\
(\mu \mathrm{m})\end{array}$ & \\
\hline $450{ }^{\circ} \mathrm{C}$ & $20 \% \mathrm{~N}_{2} / 80 \% \mathrm{Ar}$ & & 50 & 180 & 11.2 \\
& $40 \% \mathrm{~N}_{2} / 60 \% \mathrm{Ar}$ & $30-35$ & $120-150$ & 11.4 \\
& $60 \% \mathrm{~N}_{2} / 40 \% \mathrm{Ar}$ & & $15-20$ & $80-90$ & 11.8 \\
$480{ }^{\circ} \mathrm{C}$ & $20 \% \mathrm{~N}_{2} / 80 \% \mathrm{Ar}$ & & 70 & $220-240$ & 11.5 \\
& $40 \% \mathrm{~N}_{2} / 60 \% \mathrm{Ar}$ & $35-40$ & $180-190$ & 11.9 \\
$510{ }^{\circ} \mathrm{C}$ & $60 \% \mathrm{~N}_{2} / 40 \% \mathrm{Ar}$ & 25 & $140-160$ & 12.2 \\
& $20 \% \mathrm{~N}_{2} / 80 \% \mathrm{Ar}$ & 100 & 380 & 12.4 \\
& $40 \% \mathrm{~N}_{2} / 60 \% \mathrm{Ar}$ & 80 & $320-350$ & 12.8 \\
& $60 \% \mathrm{~N}_{2} / 40 \% \mathrm{Ar}$ & $60-70$ & $220-240$ & 13.1 \\
\hline
\end{tabular}

Table 9. The influence of the holding time during nitriding on the layer thickness and maximum microhardness of surface layer of high-speed steel of the gear-shaping cutters at a process temperature of $480^{\circ} \mathrm{C}$ and gas ratio was $40 \% \mathrm{~N}_{2} / 60 \%$ Ar.

\begin{tabular}{llll}
\hline $\begin{array}{l}\text { Holding time at } \\
\text { nitriding }(\mathrm{min})\end{array}$ & $\begin{array}{l}\text { Productive thickness } \\
(\mu \mathrm{m})\end{array}$ & $\begin{array}{l}\text { Total thickness } \\
(\mu \mathrm{m})\end{array}$ & $\begin{array}{l}\text { Maximum microhardness } \\
(\mathrm{GPa})\end{array}$ \\
\hline 30 & 32 & 120 & 11.6 \\
45 & $35-40$ & $180-190$ & 11.9 \\
60 & 55 & 320 & 12.2 \\
\hline
\end{tabular}

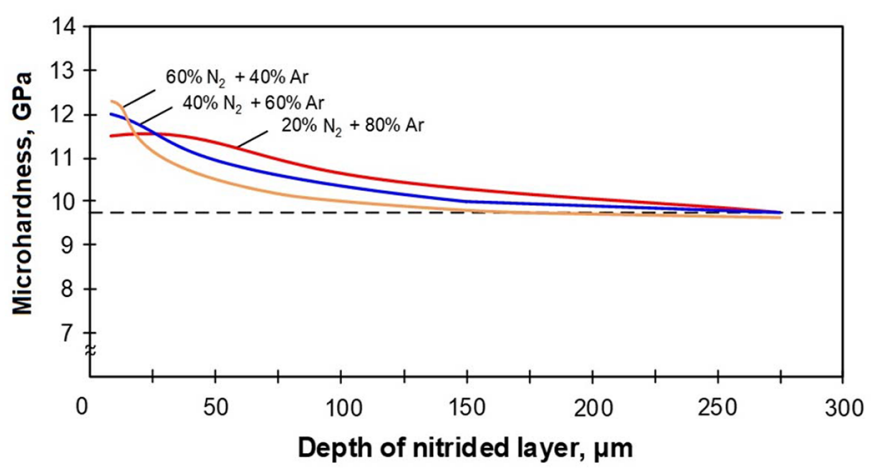

Fig. 6. The microhardness distribution in the surface nitrided layer of high-speed steel of the gear-shaping cutters at holding time for nitriding with nitrogen ions of $45 \mathrm{~min}$.

of the nitrided layer after coating on it. For example, the total thickness of the nitrided layer, formed at a temperature of $510^{\circ} \mathrm{C}$, holding time of $45 \mathrm{~min}$, in a gas environment of $20 \% \mathrm{~N}_{2}+80 \%$ Ar after deposition of the coating $(\mathrm{Nb}-\mathrm{Ti}-\mathrm{Al}-\mathrm{V}) \mathrm{N}$ increased from $300-320$ to $420-440 \mu \mathrm{m}$. An increase was about $35 \%$. At the same time, the productive thickness practically does not increase. After coating, the hardness of the nitrided layer changes very slightly: a decrease of no more than $0.2 \mathrm{GPa}$. Figure 8 shows selective microsections of high-speed steel after duplex treatment, which illustrate the changes occurring in the nitrided layer.

Table 12 shows the effect of the coating process of $(\mathrm{Nb}-\mathrm{Ti}-\mathrm{Al}-\mathrm{V}) \mathrm{N}$ on the characteristics of the nitrided layer of high-speed steel of the gear-shaping cutters. As in the previous case, the thermal effect on the surface layer, which occurs during coating, has a strong influence on the characteristics of the previously formed nitrided layer. In all the studied modes of duplex treatment after coating on the nitrided layer, there is a sharp increase in the total thickness of the nitrided layer. For example, the total thickness of the nitrided layer formed at a temperature of $510^{\circ} \mathrm{C}$, the holding time of $45 \mathrm{~min}$, in the gas medium $20 \%$ $\mathrm{N}_{2}+80 \%$ Ar after deposition of (Nb-Ti-Al-V) N coating increased from $380-320$ to $500-560 \mu \mathrm{m}$. At the same time, the quantitative value of the productive thickness increases very slightly. After coating, the hardness of the nitrided layer changes to a smaller side, but not significantly, by 0.1-0.2 GPa. Figure 9 shows selective microsections of high-speed steel after duplex treatment.

Tables 11 and 12 provide more information on the dimensional wear of the teeth of cutting tools that have undergone duplex treatment under different modes of formation of the nitrided layer. It can be seen that the finishing teeth of the broach during the operation process 
Table 10. X-ray structural analysis of the phase composition of the surface layer of high-speed steel of the gear-shaping cutters after nitriding at different gas ratios at nitriding temperature of $480^{\circ} \mathrm{C}$ and holding time of $45 \mathrm{~min}$.

\begin{tabular}{llll}
\hline Phase composition & \multicolumn{2}{c}{ Volume fraction of phase (\%) in nitrided layer } \\
\cline { 2 - 4 } & $20 \% \mathrm{~N}_{2}+80 \% \mathrm{Ar}$ & $40 \% \mathrm{~N}_{2}+60 \% \mathrm{Ar}$ & $60 \% \mathrm{~N}_{2}+40 \% \mathrm{Ar}$ \\
\hline Radiation used: CuKa (shooting in sliding geometry) & & 19.9 \\
$\mathrm{Fe}_{2} \mathrm{~N}$ & - & 7.5 & 14.3 \\
$\mathrm{Mo}_{2} \mathrm{~N}$ & 20.8 & 18.7 & 26.2 \\
$\mathrm{Fe}_{3}(\mathrm{~W}, \mathrm{Mo})_{3}(\mathrm{C}, \mathrm{N})$ & 34.6 & 32.3 & 39.6 \\
$\mathrm{Fe} \alpha(\mathrm{C}, \mathrm{N})$ & 44.6 & 41.5 & \\
$\mathrm{Radiation}_{\mathrm{Fe}} \mathrm{N}$ & & & 4.1 \\
$\mathrm{Fe}_{2} \mathrm{CuKa}$ & - & - & 8.2 \\
$\mathrm{Fe}_{2} \mathrm{~N}(\mathrm{~W}, \mathrm{Mo})_{3}(\mathrm{C}, \mathrm{N})$ & 5.2 & 7.8 & 12.0 \\
$\mathrm{Fe} \alpha(\mathrm{C}, \mathrm{N})$ & 5.7 & 11.9 & 75.7 \\
\hline
\end{tabular}

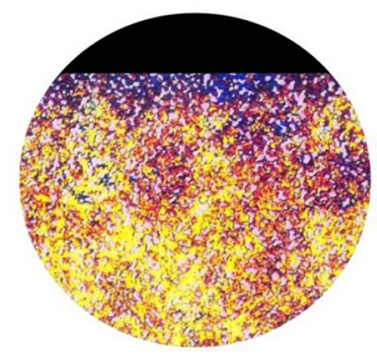

(a)

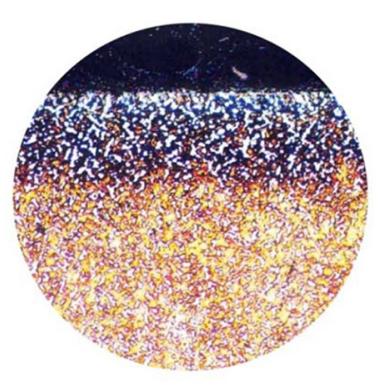

(c)

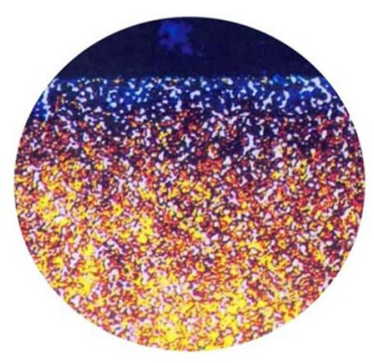

(b)

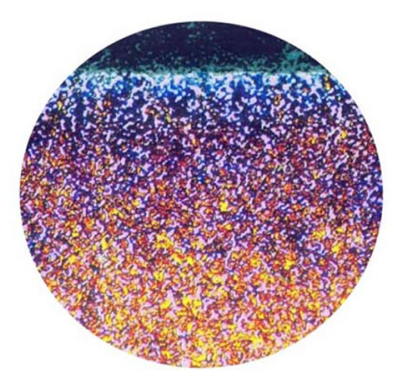

(d)

Fig. 7. Microstructures $(\times 800)$ of the surface layer of nitrided high-speed steel of the gear-shaping cutters: (a) $40 \% \mathrm{~N}_{2}+60 \%$ Ar, $480{ }^{\circ} \mathrm{C}, 30 \mathrm{~min}$; (b) $40 \% \mathrm{~N}_{2}+60 \% \mathrm{Ar}, 510{ }^{\circ} \mathrm{C}, 45 \mathrm{~min}$; (c) $60 \% \mathrm{~N}_{2}+40 \% \mathrm{Ar}, 510{ }^{\circ} \mathrm{C}, 60 \mathrm{~min}$; (d) $20 \% \mathrm{~N}_{2}+80 \% \mathrm{Ar}, 510{ }^{\circ} \mathrm{C}, 60 \mathrm{~min}$.

(Tab. 11) only due to the change in the ratio of $\mathrm{N}_{2} /$ Ar gases during nitriding at other constant modes of duplex treatment have a doubled difference in the wear intensity. The spread of average values of wear was not more than $\pm 15 \mu \mathrm{m}$. Table 12 shows that the dimensional wear of gear-shaping cutter during processing depending on the modes the duplex treatment (changed the ratio of gases during nitriding) has a three-fold difference. The spread of wear was not more than $\pm 20 \mu \mathrm{m}$. Noteworthy is the fact that the maximum wear for broaches and gear-shaping cutters is observed in the case where the nitrided layer was formed at a gas ratio of $60 \% \mathrm{~N}_{2} / 40 \% \mathrm{Ar}$.
The above results of experimental studies are far from complete since the volume of the scientific article cannot accommodate the entire array of the obtained data. It is obvious that the choice of rational modes of duplex treatment should be based on a set of interdependent parameters and be sure to take into account the results of performance tests. Taking into account that the cutting tool, which is the object of this work, is complicated and expensive, the authors conducted the minimum required amount of operational tests to obtain reliable information. For processing the experimental data and establishing rational modes, we relied on the mathematical apparatus 
Table 11. The effect of the process of coating $(\mathrm{Nb}-\mathrm{Ti}-\mathrm{Al}-\mathrm{V}) \mathrm{N}$ on the characteristics of the pre-nitrided high-speed steel of the broaches for herringbone type joint at nitriding temperature of $510^{\circ} \mathrm{C}$ and holding time of 45 min and wear resistance in the cutting process.

\begin{tabular}{llllll}
\hline $\begin{array}{l}\text { The ratio of gases } \\
\text { when nitriding } \\
\text { (nitrogen/argon) }\end{array}$ & $\begin{array}{l}\text { The characteristics of the } \\
\text { nitrided layer of high-speed steel }\end{array}$ & & $\begin{array}{l}\text { The characteristics of } \\
\text { the } \begin{array}{c}\text { nitrided layer of high-speed } \\
\text { steel after coating }\end{array}\end{array}$ & $\begin{array}{l}\text { Wear of the tooth }(\mu \mathrm{m}) \\
\text { of broach at a cutting } \\
\text { path of } 3150 \mathrm{~mm}\end{array}$ \\
\cline { 2 - 3 } & $\begin{array}{l}\text { Total thickness } \\
(\mu \mathrm{m})\end{array}$ & $\begin{array}{l}\text { Microhardness } \\
(\mathrm{GPa})\end{array}$ & $\begin{array}{l}\text { Total thickness } \\
(\mu \mathrm{m})\end{array}$ & $\begin{array}{l}\text { Microhardness } \\
(\mathrm{GPa})\end{array}$ & \\
\hline $20 \% \mathrm{~N}_{2} / 80 \% \mathrm{Ar}$ & $300-320$ & 12.9 & $420-440$ & 12.7 & 100 \\
$40 \% \mathrm{~N}_{2} / 60 \% \mathrm{Ar}$ & $250-270$ & 13.5 & $340-370$ & 13.3 & 140 \\
$60 \% \mathrm{~N}_{2} / 40 \% \mathrm{Ar}$ & 180 & 14.0 & 260 & 14.0 & 220 \\
\hline
\end{tabular}

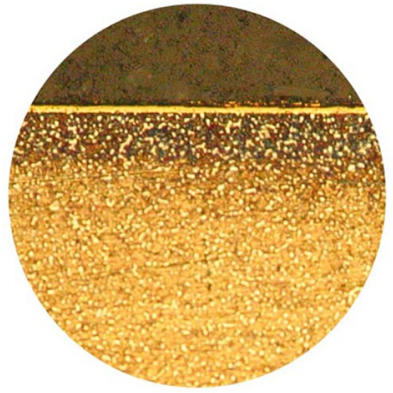

(a)

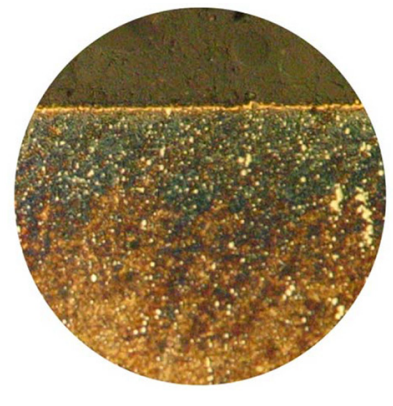

(b)
Fig. 8. Microstructures $(\times 750)$ of the surface layer of high-speed steel used for the manufacture of the broaches for herringbone type joint after duplex treatment: (a) after nitriding at $40 \%$ $\mathrm{N}_{2}+60 \%$ Ar, $480^{\circ} \mathrm{C}, 30$ min and coating with $(\mathrm{Nb}-\mathrm{Ti}-\mathrm{Al}-\mathrm{V}) \mathrm{N}$; (b) after nitriding at $20 \% \mathrm{~N}_{2}+80 \% \mathrm{Ar}, 510^{\circ} \mathrm{C}, 60 \mathrm{~min}$ and coating with $(\mathrm{Nb}-\mathrm{Ti}-\mathrm{Al}-\mathrm{V}) \mathrm{N}$.

and used the software complex Statistica (TIBCO, Palo Alto, CA, USA). Table 13 presents rational (recommended) modes of duplex treatment: nitriding and subsequent coating $(\mathrm{Nb}-\mathrm{Ti}-\mathrm{Al}-\mathrm{V}) \mathrm{N}$ in a single technological cycle for two types of complex-profile tools.

\subsection{The influence of the duplex treatment on wear resistance of complex-high-speed steel tool in the process of operation}

In the final part of the research, the task was to assess the impact of duplex treatment on tool wear in conditions as close as possible to the real production and to compare the cutting tools. Sets of tools made of high-speed steels that have undergone various types of surface treatment were prepared.

The problems that can be solved by coating deposition on the working surfaces of the tool consist mainly in increasing the microhardness of the contact surfaces that touch the processed material and reducing the friction coefficient during contacts with the part. For processing of nickel-based heat-resistant alloys, first of all, it is necessary to make sure that the proposed coating successfully solves the problem of reducing the intensity of adhesion of the processed material to the cutting tool.
Due to the specific physical and mechanical properties of nickel-based alloys, increased specific forces occur during machining, which leads to an increase in power and thermal loads in the cutting zone, it is difficult to remove heat from the cutting zone. Due to the strong adhesive interaction, nickel adheres and is welded to the cutting tool. It leads to a change in the geometric parameters and the further increase in processing effort and intensifies tool wear.

For studying the adhesion process of nickel, three types of tools were manufactured and then investigated: the first one without surface treatment, the second one with ion nitriding, and the third one with duplex treatment. All tools were worn to a level of $100 \mu \mathrm{m}$ during operation. Then the working surfaces of the tools were studied at SEM. Figure 10 shows images that demonstrate the intensity of nickel adhesion to the front surface of the gear-shaping cutter during operation. The similar results were obtained when studying the front surfaces of the broaches.

SEM-images demonstrate that during the operation of gear-shaping cutters without treatment, an intense adhesion and welding of nickel particles to the front surface of the tool from the outgoing chips were observed. Nitriding does not have a serious effect on the intensity of setting of the front surface of the tool with the processed fine particles of nickel, the number, and size of which are incomparably smaller.

The results of operational tests of preliminary and final broaches are presented in Figures 11 and 12. For comparison, five types of tools were used: tools without surface treatment; tools with $(\mathrm{Nb}-\mathrm{Ti}-\mathrm{Al}-\mathrm{V}) \mathrm{N}$ coating; tools after nitriding at $60 \% \mathrm{~N}_{2}+40 \% \mathrm{Ar}, 480{ }^{\circ} \mathrm{C}, 60 \mathrm{~min}$ and with $(\mathrm{Nb}-\mathrm{Ti}-\mathrm{Al}-\mathrm{V}) \mathrm{N}$ coating; tools after nitriding at $20 \% \mathrm{~N}_{2}+80 \% \mathrm{Ar}, 480^{\circ} \mathrm{C}, 60$ min and with $(\mathrm{Nb}-\mathrm{Ti}-\mathrm{Al}-\mathrm{V}) \mathrm{N}$ coating; and tools after nitriding at $40 \% \mathrm{~N}_{2}+60 \% \mathrm{Ar}, 480^{\circ} \mathrm{C}$, $60 \mathrm{~min}$ and with (Nb-Ti-Al-V) $\mathrm{N}$ coating (rational mode). Figure 13 shows the images of the nature of the wear of the preliminary teeth of the broach during the operational tests.

It can be seen that the dependence of the broach wear on the time of the cutting process, regardless of the type of surface treatment, obeys the classical law. First, there is a tool burn-in, accompanied by excessive tool flank wear, then begins the period of stabilization of wear, which is characterized by a slowdown in the intensity of wear and then follows the stable operation of the tool with slowly 


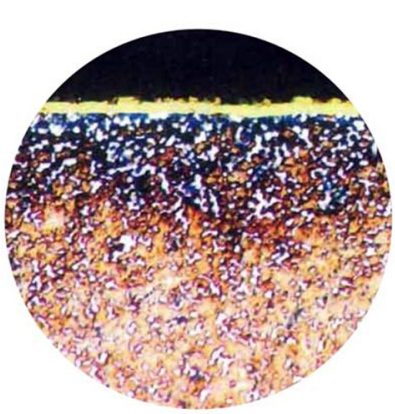

(a)

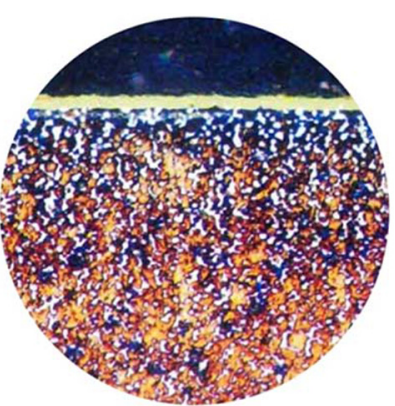

(b)

Fig. 9. Microstructures $(\times 800)$ of the surface layer of nitrided high-speed steel used for the a gear-shaping cutter: (a) after nitriding at $40 \% \mathrm{~N}_{2}+60 \% \mathrm{Ar}, 480^{\circ} \mathrm{C}, 30 \mathrm{~min}$ and $(\mathrm{Nb}-\mathrm{Ti}-\mathrm{Al}-\mathrm{V}) \mathrm{N}$ coating; (b) after nitriding at $20 \% \mathrm{~N}_{2}+80 \% \mathrm{Ar}, 510{ }^{\circ} \mathrm{C}, 60 \mathrm{~min}$ and $(\mathrm{Nb}-\mathrm{Ti}-\mathrm{Al}-\mathrm{V}) \mathrm{N}$ coating.

Table 12. The effect of the coating process $(\mathrm{Nb}-\mathrm{Ti}-\mathrm{Al}-\mathrm{V}) \mathrm{N}$ on the characteristics of the pre-nitrided high-speed steel of the gear-shaping cutters at nitriding temperature of $510^{\circ} \mathrm{C}$ and holding time of $45 \mathrm{~min}$ and wear resistance in the cutting process.

\begin{tabular}{|c|c|c|c|c|c|}
\hline \multirow[t]{2}{*}{$\begin{array}{l}\text { The ratio of gases } \\
\text { when nitriding } \\
\text { (nitrogen/argon) }\end{array}$} & \multicolumn{2}{|c|}{$\begin{array}{c}\text { The characteristics of } \\
\text { the nitrided layer of } \\
\text { high-speed steel }\end{array}$} & \multicolumn{2}{|c|}{$\begin{array}{l}\text { The characteristics of the } \\
\text { nitrided layer of high-speed } \\
\text { steel after coating }\end{array}$} & \multirow[t]{2}{*}{$\begin{array}{l}\text { Wear of the tooth }(\mu \mathrm{m}) \\
\text { of the gear-shaping cutter } \\
\text { after } 50 \text { min of work }\end{array}$} \\
\hline & $\begin{array}{l}\text { Total } \\
\text { thickness } \\
(\mu \mathrm{m})\end{array}$ & $\begin{array}{l}\text { Microhardness } \\
(\mathrm{GPa})\end{array}$ & $\begin{array}{l}\text { Total } \\
\text { thickness } \\
(\mu \mathrm{m})\end{array}$ & $\begin{array}{l}\text { Microhardness } \\
(\mathrm{GPa})\end{array}$ & \\
\hline $20 \% \mathrm{~N}_{2} / 80 \% \mathrm{Ar}$ & 380 & 12.4 & $500-560$ & 12.2 & 110 \\
\hline $40 \% \mathrm{~N}_{2} / 60 \% \mathrm{Ar}$ & $320-350$ & 12.8 & $400-440$ & 12.6 & 175 \\
\hline $60 \% \mathrm{~N}_{2} / 40 \% \mathrm{Ar}$ & $220-240$ & 13.1 & $350-380$ & 13.0 & 320 \\
\hline
\end{tabular}

Table 13. Recommended modes of duplex treatment as nitriding and coating with ( $\mathrm{Nb}-\mathrm{Ti}-\mathrm{Al}-\mathrm{V}) \mathrm{N}$ in a single technological cycle for different types of complex profile tools made of high-speed steels, and characteristics of the formed surface layer.

\begin{tabular}{|c|c|c|c|c|c|c|c|}
\hline \multirow[t]{3}{*}{ Cutting tool } & \multirow[t]{3}{*}{$\begin{array}{l}\text { The ratio of gases } \\
\text { when nitriding } \\
\text { (nitrogen/argon) }\end{array}$} & \multirow[t]{3}{*}{$\begin{array}{l}\text { The temperature of } \\
\text { the nitriding } \\
\text { process }\left({ }^{\circ} \mathrm{C}\right)\end{array}$} & \multirow[t]{3}{*}{$\begin{array}{l}\text { Holding time at } \\
\text { nitriding }(\mathrm{min})\end{array}$} & \multicolumn{4}{|c|}{$\begin{array}{c}\text { The characteristics of the surface } \\
\text { layer of the high-speed } \\
\text { tool after duplex } \\
\text { treatment }\end{array}$} \\
\hline & & & & \multirow[b]{2}{*}{$\begin{array}{l}\text { The } \\
\text { productive } \\
\text { thickness } \\
\text { of the } \\
\text { nitrided } \\
\text { layer }(\mu \mathrm{m})\end{array}$} & \multirow{2}{*}{$\begin{array}{l}\text { The total } \\
\text { thickness } \\
\text { of the } \\
\text { nitrided } \\
\text { layer }(\mu \mathrm{m})\end{array}$} & \multicolumn{2}{|c|}{ Microhardness } \\
\hline & & & & & & $\begin{array}{l}\text { Nitrided } \\
\text { layer } \\
\text { (GPa) }\end{array}$ & $\begin{array}{l}\text { Coating } \\
(\mathrm{GPa})\end{array}$ \\
\hline $\begin{array}{l}\text { Broach for } \\
\text { herringbone } \\
\text { type joint }\end{array}$ & $40 \% \mathrm{~N}_{2} / 60 \% \mathrm{Ar}$ & 480 & 60 & $50-53$ & 360 & 12.7 & $27.5 \pm 0.5$ \\
\hline $\begin{array}{l}\text { Gear-shaping } \\
\text { cutter }\end{array}$ & $20 \% \mathrm{~N}_{2} / 80 \% \mathrm{Ar}$ & 480 & 45 & $72-74$ & $330-350$ & 11.5 & $27.5 \pm 0.5$ \\
\hline
\end{tabular}

developing flank wear. This pattern of wear development is observed in broaches regardless of the feed rate per tooth $(0.02$ and $0.07 \mathrm{~mm} /$ tooth $)$. For the quantitative values of wear at different points in time, there is a significant difference. The tool with duplex treatment, nitriding of which was carried out in an environment of $60 \% \mathrm{~N}_{2}+40 \% \mathrm{Ar}$, wears out more intensively (in 1.4-1.5 times) than the tool without any treatment and coating. 

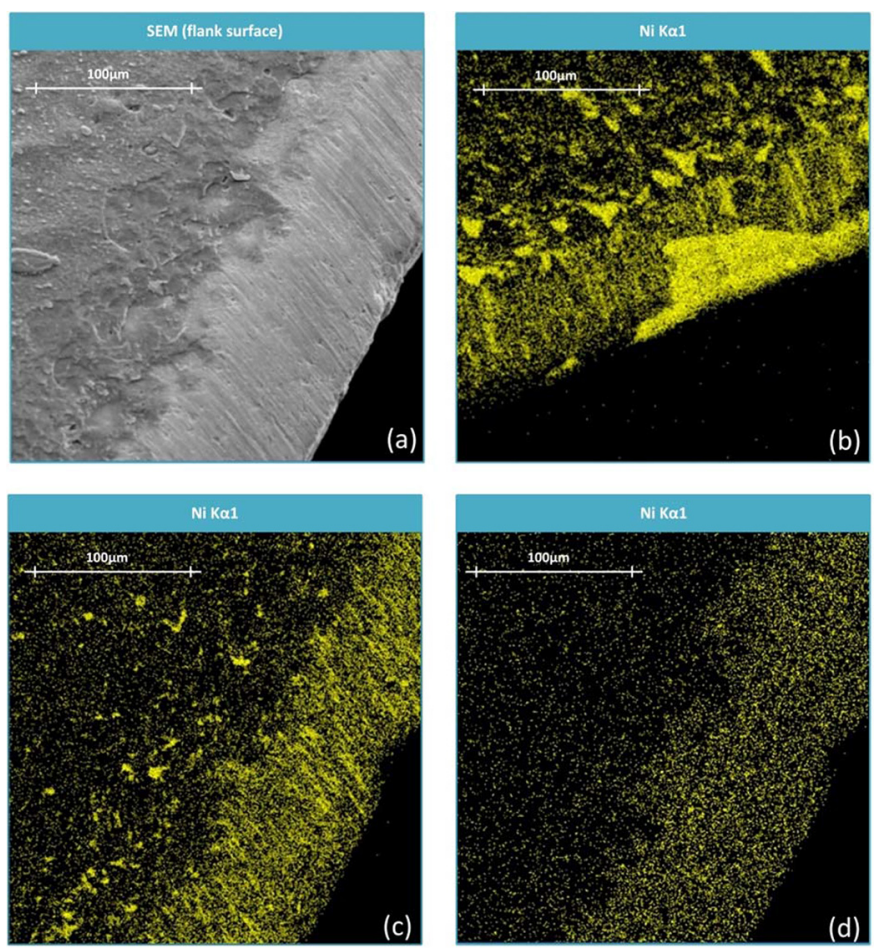

Fig. 10. The distribution of nickel (yellow particles) on the front surface of the worn gear-shaping cutters made of high-speed steel: (a) SEM-image of the front surface; (b) tool without surface treatment; (c) tool after ion nitriding; and (d) tool after duplex treatment.

Thus, the tool subjected to duplex treatment on the rational modes established earlier shows a decrease in the value of wear in two times in comparison with the tool without treatment. It is worth emphasizing that the coating ( $\mathrm{Nb}-\mathrm{Ti}-\mathrm{Al}-\mathrm{V}) \mathrm{N}$ deposited on non-nitrided highspeed steel does not have a significant impact on the wear resistance of the tool.

For comparison of gear-shaping cutters, five types of tools were used: a tool without surface treatment; a coated tool with $(\mathrm{Nb}-\mathrm{Ti}-\mathrm{Al}-\mathrm{V}) \mathrm{N}$; a tool nitrided at $60 \%$ $\mathrm{N}_{2}+40 \% \mathrm{Ar}, 480^{\circ} \mathrm{C}, 45 \mathrm{~min}$ and with $(\mathrm{Nb}-\mathrm{Ti}-\mathrm{Al}-\mathrm{V}) \mathrm{N}$ coating; a tool nitride at $20 \% \mathrm{~N}_{2}+80 \% \mathrm{Ar}, 480{ }^{\circ} \mathrm{C}$ (rational mode), $45 \mathrm{~min}$ and with coating $(\mathrm{Nb}-\mathrm{Ti}-\mathrm{Al}-\mathrm{V}) \mathrm{N}$; and a tool nitrided at $40 \% \mathrm{~N}_{2}+60 \% \mathrm{Ar}, 480^{\circ} \mathrm{C} 45 \mathrm{~min}$ with coating $(\mathrm{Nb}-\mathrm{Ti}-\mathrm{Al}-\mathrm{V}) \mathrm{N}$.

Figure 14 presents the results of operational tests of gear-shaping cutters. It can be seen that at the time of the tool burn-in, there is no significant influence of various options for surface treatment on the wear rate of the gearshaping cutter. In the future, the development of the focus of flank wear of gear-shaping cutter takes place according to the scheme already described for broaches. Figure 15 shows images of the nature of wear of the teeth of the gearshaping cutter during operational testing.

It is important to note that the duplex treatment (nitriding at $60 \% \mathrm{~N}_{2}+40 \% \mathrm{Ar}, 480{ }^{\circ} \mathrm{C}, 45 \mathrm{~min}$ and coating $(\mathrm{Nb}-\mathrm{Ti}-\mathrm{Al}-\mathrm{V}) \mathrm{N})$ has a very negative impact on the wear of the gear-shaping cutter: the wear rate increased by 1.8 times compared to the tool without treatment. However,

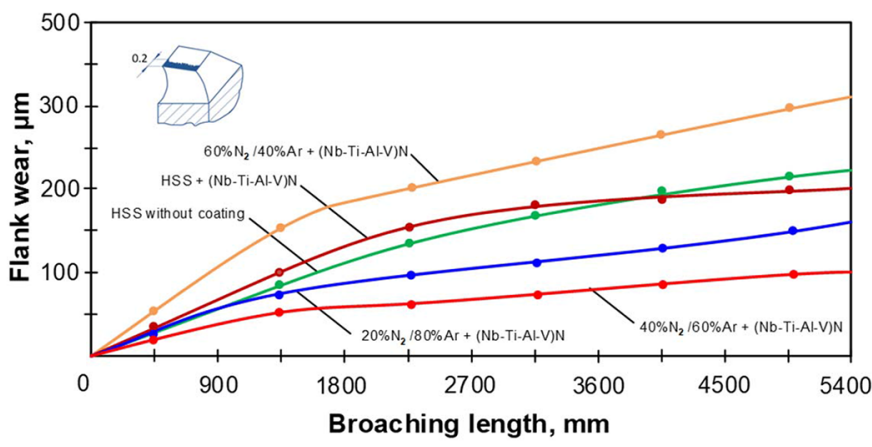

Fig. 11. The dependence of flank wear of finishing broach teeth with various surface treatment options on the broaching length during processing herringbone type joint in a heat-resistant nickel alloy (the processing speed is $3 \mathrm{~m} / \mathrm{min}$, the feed is $0.02 \mathrm{~mm} /$ tooth).

the tool, which has passed duplex treatment on rational modes, shows positive results - wear resistance is increased by two times. At the same time, the (Nb-Ti-Al-V) N coating deposited on non-nitrided high-speed steel does not have a visible effect on the wear resistance of the cutter, which once again confirms the correctness of the technological approach developed in this work.

\section{Discussion of the results}

Analysis of the data presented in Tables 5 and 8 shows that the chemical composition of high-speed steel has the most important influence on the diffusion process of nitriding and the characteristics of the formed layer.

From the foundations of the classical theory of the doping of metals and alloys, it is known that alloying elements have a different effect on the diffusion coefficient of nitrogen in iron and alloys based on it. The complex of experiments carried out in this work found that under the same conditions of nitriding the total thickness of the layer formed during nitriding of gear-shaping cutters is about $30 \%$ higher than the corresponding figure for broaches. If we analyze the data of the chemical composition of the steels studied in this paper (Tab. 1), it can be explained by the following effect of alloying elements. For example, an increase in the percentage of carbon and vanadium in high-speed steel hinders and slows down the diffusion of nitrogen. Conversely, an increase in the percentage of non-carbide-forming cobalt increases the diffusion rate of iron-based alloys. It must be emphasized that in steels obtained by powder metallurgy the diffusion intensity is higher than in steels of the same chemical composition, but obtained by casting. It is due to the higher dispersion of carbides and their uniform distribution over the cross-section of a tool made of steel, obtained by powder technology. All these specific features should be taken into account, and the nitriding modes should be optimized for each particular high-speed steel.

It is necessary to discuss the data presented in Tables 7 and 10 demonstrating that the chemical composition of steels in combination with nitriding modes (mainly the composition of the nitrogen-containing medium) determines the phase composition of the formed nitrided layer. 


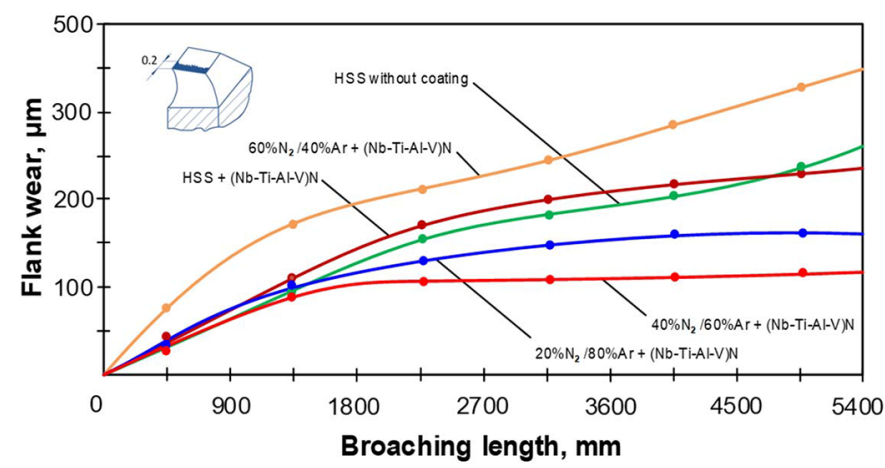

Fig. 12. The dependence of flank wear of the preliminary broach teeth with various surface treatment options on the broaching length during processing herringbone type joint in a heatresistant nickel alloy (the processing speed is $3 \mathrm{~m} / \mathrm{min}$, the feed is $0.07 \mathrm{~mm} /$ tooth).

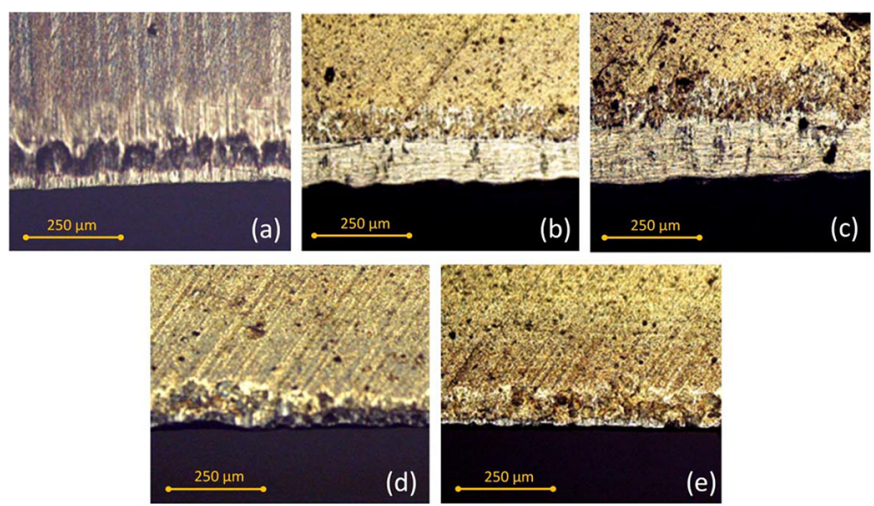

Fig. 13. The nature of wear of the preliminary broach teeth during the operational tests after the $4500 \mathrm{~mm}$ broaching length: (a) a tool without surface treatment; (b) a tool with $(\mathrm{Nb}-\mathrm{Ti}-\mathrm{Al}-\mathrm{V}) \mathrm{N}$ coating; (c) a tool after nitriding at $60 \% \mathrm{~N}_{2}+40 \% \mathrm{Ar}, 480^{\circ} \mathrm{C}, 60 \mathrm{~min}$ with (Nb-Ti-Al-V) $\mathrm{N}$ coating; (d) a tool after nitriding at $20 \% \mathrm{~N}_{2}+80 \% \mathrm{Ar}, 480^{\circ} \mathrm{C}, 60 \mathrm{~min}$ with $(\mathrm{Nb}-\mathrm{Ti}-\mathrm{Al}-\mathrm{V}) \mathrm{N}$ coating; (e) a tool after nitriding at $40 \% \mathrm{~N}_{2}+60 \% \mathrm{Ar}, 480^{\circ} \mathrm{C}, 60 \mathrm{~min}$ with $(\mathrm{Nb}-\mathrm{Ti}-\mathrm{Al}-\mathrm{V}) \mathrm{N}$ coating.

It was found that at a gas composition of $60 \% \mathrm{~N}_{2}+40 \% \mathrm{Ar}$ during nitriding of two different types of steel formed nitride phase consisting of $\varepsilon$-phase $\left(\mathrm{Fe}_{2} \mathrm{~N}\right)$ with high nitrogen content ( $24.6 \%$ is for steel broaches, $19.9 \%$ is for steel gear-shaping cutters). The formation of this phase under the coating has an extremely negative effect on the operation of the tool with duplex treatment and does not provide a good basis for the operation of the $(\mathrm{Nb}-\mathrm{Ti}-\mathrm{Al}-\mathrm{V}) \mathrm{N}$ coating. Also, the formation of the $\mathrm{Fe}_{2} \mathrm{~N}$-phase on the surface delays the diffusion of nitrogen and leads to a decrease in the effective and total thickness of the nitrided layer, and also causes embrittlement of the layer.

The data presented in Figures 11, 12, and 14 show that nitriding at $60 \% \mathrm{~N}_{2}+40 \% \mathrm{Ar}$ intensifies the wear of broaches and gear-shaping cutters in the processing of nickel alloy and significantly worsens the operating conditions of the tool compared to the original tool (without surface treatment).

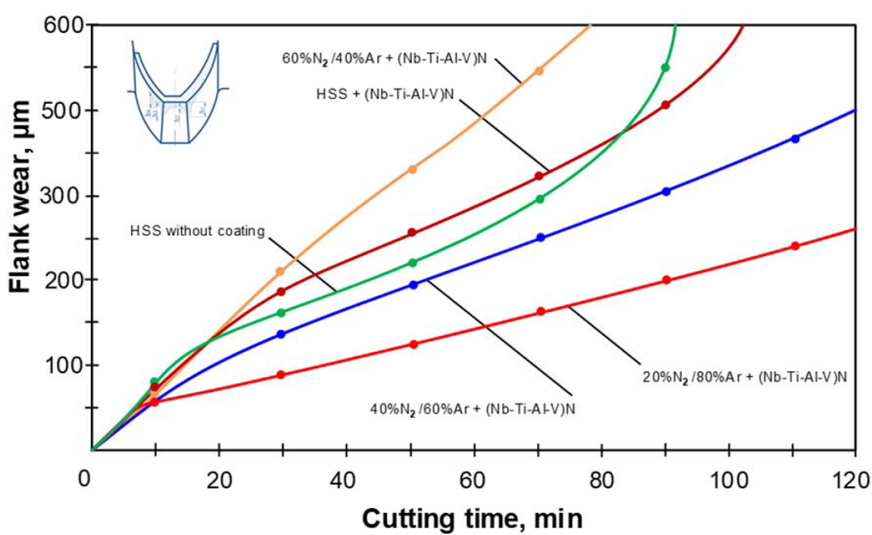

Fig. 14. The dependence of the teeth flank wear of the gearshaping cutters with different surface treatment options on the tool operation time during processing involute spline of a workpiece made of heat-resistant nickel alloy (30 double strokes of the cutter per minute; the radial feed is $0.03 \mathrm{~mm}$ /double-stroke; the circular feed is $0.121 \mathrm{~mm} /$ double-stroke).

Attention should be drawn to the fact that the composition of $40 \% \mathrm{~N}_{2}+60 \% \mathrm{Ar}$ in the surface layer of high-speed steel is re-detected the $\mathrm{Fe}_{2} \mathrm{~N}$ phase in an amount of $7.5 \%$ (Tab. 10). In the process of operational tests, the duplex treated cutter nitrided at $40 \% \mathrm{~N}_{2}+60 \%$ Ar (i.e., having $\mathrm{Fe}_{2} \mathrm{~N}$ in the phase composition even in a small amount) does not show satisfactory results (Fig. 14). The X-ray analysis (Tab. 7) shows another consequence after nitriding high-speed steel broaches: when the ratio of gases is $40 \% \mathrm{~N}_{2}+60 \% \mathrm{Ar}, \mathrm{Fe}_{2} \mathrm{~N}$ phase is not formed, and the broaches with duplex treatment show the maximum effect in the process of operation (Figs. 11 and 12).

Thus, both for broaches and gear-shaping cutters, it is necessary to aim for the formation of a nitrided layer containing a large amount of phase based on a solid solution of nitrogen in martensite and to prevent the formation of the $\mathrm{Fe}_{2} \mathrm{~N}$ phase. At the same time, it should be understood that excessive dilution of nitrogen with inert argon gas is also impractical, since the less nitrogen in the gas medium, the lower the hardness of the nitrided layer formed. For broaches the optimal gas ratio is $40 \% \mathrm{~N}_{2}+60 \% \mathrm{Ar}$, for gear-shaping cutters it is $20 \% \mathrm{~N}_{2}+80 \% \mathrm{Ar}$. It can be concluded that by varying nitrogen and argon in the composition of the gaseous medium by nitriding with nitrogen ions, the required phase composition under the coating and the required characteristics for different tools depending on the operating conditions can be obtained.

A set of experiments to study the effect of temperature and duration of the nitriding process on the characteristics of the nitrided layer (microhardness and thickness) show that optimization is also necessary. General regularities in nitriding of various high-speed steels were established (Tabs. 6 and 9), while the rational modes for different operating conditions of the tool are significantly different. It is important to remember that the coating $(\mathrm{Nb}-\mathrm{Ti}-\mathrm{Al}-\mathrm{V}) \mathrm{N}$ makes additional adjustments to the characteristics of the previously formed layer, as well as any other composition. In the duplex treatment of the broaches, the optimal is nitriding at $40 \% \mathrm{~N}_{2}+60 \% \mathrm{Ar}$, 

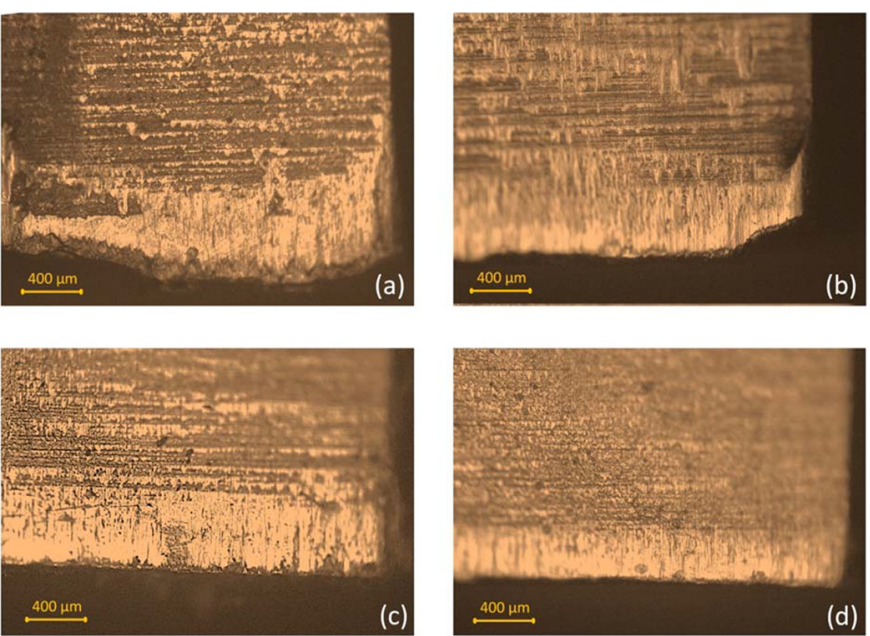

Fig. 15. The nature of the teeth wear of gear-shaping cutter during testing after 70 min of work: (a) the nitrided tool at $60 \%$ $\mathrm{N}_{2}+40 \%$ Ar, $480{ }^{\circ} \mathrm{C}, 45 \mathrm{~min}$, with (Nb-Ti-Al-V) N coating; (b) the tool without surface treatment; (c) the nitrided tool at $40 \% \mathrm{~N}_{2}+60 \% \mathrm{Ar}, 480^{\circ} \mathrm{C}, 45 \mathrm{~min}$, with (Nb-Ti-Al-V) N coating; (d) the nitrided tool at $20 \% \mathrm{~N}_{2}+80 \% \mathrm{Ar}, 480{ }^{\circ} \mathrm{C}, 45 \mathrm{~min}$, with $(\mathrm{Nb}-\mathrm{Ti}-\mathrm{Al}-\mathrm{V}) \mathrm{N}$ coating.

$480^{\circ} \mathrm{C}$, for $60 \mathrm{~min}$. In such conditions, a layer of the microhardness of $12.7 \mathrm{GPa}$ with the productive thickness of $50-53 \mu \mathrm{m}$ and the total thickness of $360 \mu \mathrm{m}$ is formed. In the duplex treatment of gear-shaping cutters recommended mode is following: $20 \% \mathrm{~N}_{2}+80 \% \mathrm{Ar}, 480^{\circ} \mathrm{C}$, $45 \mathrm{~min}$, which forms a layer of the microhardness of $11.5 \mathrm{GPa}$ with the productive thickness of $72-74 \mu \mathrm{m}$ and the total thickness of $330-350 \mu \mathrm{m}$.

It is important to pay attention to the results of operational tests once again (Figs. 11, 12, and 14), in the course of that test the authors deliberately used tools with the coating $(\mathrm{Nb}-\mathrm{Ti}-\mathrm{Al}-\mathrm{V})$ only to determine the role of nitriding in the technological process. A little surprising is the fact that the coating does not change the nature or intensity of wear of broaches and cutters during operation and shows the result as close to the operation of the original tool without surface treatment as possible. It can mean only one thing, that in the first minutes of the tool's work the coating ceases to function and the conditions of the interaction of the processed material with the front, and flank surfaces of the tool are as close as possible to the original tool. In some well-known works, the nitriding of high-speed steels before the coating is considered as an auxiliary operation, which further increases the durability of the coated tool. In the context of this work, when two rather complicated production operations (broaching and slotting) are considered from the loads that the cutting tool experiences and the processing of a hard-to-work nickel-based alloy are performed, the nitriding is not an auxiliary, but a basic operation. Even the most promising coating in such conditions is not able to resist current loads. Performing nitriding on the rational modes established in the present work, and subsequent coating $(\mathrm{Nb}-\mathrm{Ti}-\mathrm{Al}-\mathrm{V}) \mathrm{N}$ allows to achieve the desired result and significantly (in approximately two times) increase the wear resistance of expensive broaches and gear-shaping cutters in the production of aircraft engine parts made of nickel-based alloys.

\section{Conclusion}

The presented study showed the effect of duplex vacuumplasma treatment, which includes successive ion nitriding and coating $(\mathrm{Nb}-\mathrm{Ti}-\mathrm{Al}-\mathrm{V}) \mathrm{N}$, on the characteristics of the surface layer and the wear intensity of the herringbone broaches and gear-shaping cutters, made of high-speed steel alloy powders, in the processing of nickel-based alloy. The presented complex of experimentally obtained results demonstrates how favorably the proposed technology approach influences the process of cutting.

The chemical composition of high-speed steel has a great impact on the diffusion process of nitriding and the characteristics of the forming layer. By varying the ratio of nitrogen and argon in the gas medium during nitriding with nitrogen ions, the required phase composition under the coating can be obtained. Depending on the operating conditions, the necessary optimal characteristics for various tools can be revealed. The holding time during nitriding and the temperature mode of the process have a determining effect on the thickness and microhardness of the nitrided layer. In this case, the coating $(\mathrm{Nb}-\mathrm{Ti}-\mathrm{Al}-\mathrm{V}) \mathrm{N}$ makes additional adjustments to the characteristics of the previously formed layer.

The duplex treatment of broaches nitriding at following conditions can be optimal: the medium is $40 \%$ $\mathrm{N}_{2}+60 \%$ Ar, the holding temperature is $480{ }^{\circ} \mathrm{C}$, and the holding time is $60 \mathrm{~min}$. In such conditions, a layer with the microhardness of $12.7 \mathrm{GPa}$, and the productive thickness of $50-53 \mu \mathrm{m}$, and the total thickness of $360 \mu \mathrm{m}$ is formed. For the duplex treatment of gear-shaping cutters, the recommended mode is the following: $20 \% \quad \mathrm{~N}_{2}+80 \%$ $\mathrm{Ar}, 480^{\circ} \mathrm{C}, 45 \mathrm{~min}$. It forms a layer with the microhardness of $11.5 \mathrm{GPa}$, and the productive thickness of $72-74 \mu \mathrm{m}$, and the total thickness of $330-350 \mu \mathrm{m}$.

Duplex treatment has a significant positive influence on the intensity of the adhesion and welding of nickel particles to the front surface of broaches and gear-shaping cutters while conducting nitriding only has no significant impact on the process. Only duplex treatment minimizes the process of setting compared to the operation of a tool without surface treatment.

Ion nitriding and coating with $(\mathrm{Nb}-\mathrm{Ti}-\mathrm{Al}-\mathrm{V}) \mathrm{N}$ can be recommended as an effective means of improving the operational stability of complex high-speed tools as broaches for herringbone type joint and gear-shaping cutters in the processing of nickel-based alloys. Operational tests have shown that the wear resistance of two types of expensive complex tools can be increased by two times during the duplex treatment according to the recommended modes.

Acknowledgements. This project has received funding from the Ministry of Education and Science of the Russian Federation within the framework of the state task for scientific research, under Grant Agreement No. 9.1372.2017/4.6. 


\section{References}

[1] H. Meier, K. Ninomiya, D. Dornfeld, V. Schulze, Hard broaching of case hardened SAE 5120, Proc. CIRP 14 (2014) 60-65

[2] P.N. Filatov, Influence of ionic-plasma hardening on the performance of broaches in machining high-temperature nickel alloys, Russ. Eng. Res. 29 (2009) 732-734

[3] A. Hosseini, H.A. Kishawy, On the optimized design of broaching tools, J. Manuf. Sci. Eng. 136 (2014) 011011

[4] A. Katz, K. Erkorkmaz, F. Ismail, Virtual model of gear shaping-Part I: kinematics, cutter-workpiece engagement, and cutting forces, J. Manuf. Sci. Eng. 140 (2018) 071007

[5] M. Braic, V. Braic, M. Balaceanu, A. Vladescu, C.N. Zoita, C.P. Lungu, C.E.A. Grigorescu, E. Grigore, C. Logoftu, $(\mathrm{Ti}, \mathrm{Cr}, \mathrm{Nb}) \mathrm{CN}$ coatings deposited on nitrided high-speed steel by cathodic arc method, Surf. Coat. Technol. 205 (2011) 209-213

[6] M. Lamraoui, M. El Badaoui, F. Guilleti, Chatter stability prediction for $\mathrm{CNC}$ machine tool in operating condition through operational modal analysis, Mech. Ind. 17 (2016) 402

[7] A. Metel, M. Volosova, S. Grigoriev, Yu. Melnik, Products pre-treatment and beam-assisted deposition of magnetron sputtered coatings using a closed cylindrical grid inside a planetary rotation system, Surf. Coat. Technol. 325 (2017) 327-332

[8] V. Yu. Fominski, S.N. Grigoriev, A.G. Gnedovets et al., Pulsed laser deposition of composite Mo-Se-Ni-C coatings using standard and shadow mask configuration, Surf. Coat. Technol. 206 (2012) 5046-5054

[9] E.A. Levashov, A.S. Mukasyan, A.S. Rogachev, D.V. Shtansky. Self-propagating high-temperature synthesis of advanced materials and coatings, Int. Mater. Rev. 62 (2017) 203-239

[10] M. Azadi, A.S. Rouhaghdam, S. Ahangarani, Mechanical behavior of $\mathrm{TiN} / \mathrm{TiC}-\mathrm{n}$ multilayer coatings and $\mathrm{Ti}(\mathrm{C}, \mathrm{N})$ multicomponent coatings produced by PACVD, Strength Mater. 8 (2016) 279-289

[11] M. Volosova, S. Grigoriev, A. Metel, A. Shein, The role of thin-film vacuum-plasma coatings and their influence on the efficiency of ceramic cutting inserts, Coatings 8 (2018) 287

[12] O.V. Sobol', A.A. Andreev, S.N. Grigoriev, M.A. Volosov, V.F. Gorban', Vacuum-arc multilayer nanostructured TiN/ Ti coatings: structure, stress state, properties, Met. Sci. Heat Treat. 54 (2012) 28-33

[13] K. Mughal, M. Saleem, M. Pervez Mughal, Performance evaluation of nano-composite ceramic-coated high-speed steel (HSS) drills in high-speed machining, Int. J. Adv. Manuf. Technol. 96 (2018) 4195-4203

[14] M. Sahin, C. Misirli, D. Özkan, Characteristic properties of AlTiN and TiN coated HSS materials, Ind. Lubr. Tribol. 67 (2015) 172-180

[15] V.V. Kuzin, M. Yu. Fedorov, M.A. Volosova, Nitride ceramic surface layer stressed state transformation with a change in TiC-coating thickness. Stress - distributed force load version, Refract. Ind. Ceram. 57 (2017) 551-556

[16] M.A. Volosova, S.N. Grigoriev, E.A. Ostrikov, Use of laser ablation for formation of discontinuous (discrete) wearresistant coatings formed on solid carbide cutting tool by electron beam alloying and vacuum-arc deposition, Mech. Ind. 17 (2016) 720

[17] S.N. Grigoriev, A.S. Metel, S.V. Fedorov, Modification of the structure and properties of high-speed steel by combined vacuum-plasma treatment, Met. Sci. Heat Treat. 54 (2012) 8-12
[18] W. Wu, W. Chen, S. Yang, Y. Lin, S. Zhang, T.Y. Cho, G.H. Lee, S.C. Kwon, Design of AlCrSiN multilayer and nanocomposite coating for HSS cutting tools, Appl. Surf. Sci. 351 (2015) 803-810

[19] C. Tritremmel, R. Daniel, M. Lechthaler, P. Polcik, C. Mitterer, Influence of $\mathrm{Al}$ and $\mathrm{Si}$ content on structure and mechanical properties of arc evaporated Al-Cr-Si-N thin films, Thin Solid Films 534 (2013) 403-409

[20] L.F. Zagonel, E. J. Mittemeijer, F. Alvarez, Microstructure of tool steel after low temperature ion nitriding, Mater. Sci. Technol. 25 (2009) 726-732

[21] T. Aiso, U. Wiklund, M. Kubota, S. Jacobson, Influence of $\mathrm{Mn}$ and $\mathrm{Al}$ additions to carbon steel on material transfer and coating damage mechanism in a sliding contact between steel and TiN coated HSS tool, Tribol. Int. 101 (2016) 414-424

[22] P. Saikia, A. Joseph, R. Rane, B.K. Saikia, S. Mukherjee, Role of substrate and deposition conditions on the texture evolution of titanium nitride thin film on bare and plasmanitrided high-speed steel, J. Theor. Appl. Phys. 66 (2013) $1-12$

[23] M.K. Skakov, B.K. Rakhadilov, M. Sheffler, Modification of structure and properties of steel R6M5 at electrolyte plasma treatment, Adv. Mater. Res. 601 (2013) 64-68

[24] A.F. Rousseau, J.G. Partridge, E.L.H. Mayes, J.T. Toton, M. Kracica, D.G. McCulloch, E.D. Doyle, Microstructural and tribological characterisation of a nitriding/TiAlN PVD coating duplex treatment applied to M2 High Speed Steel tools, Surf. Coat. Technol. 272 (2015) 403-408

[25] B. Miao, Y. Chai, K. Wei, J. Hu, A novel duplex plasma treatment combining plasma nitrocarburizing and plasma nitriding, Vacuum 133 (2016) 54-57

[26] A. Nishimoto, H. Nii, R. Narita, K. Akamatsu, Simultaneous duplex process of TiN coating and nitriding by active screen plasma nitriding, Surf. Coat. Technol. 228 (2012) 558-562

[27] E.D. Doyle, A. Pagon, P. Hubbard, S. Dowey, A. Pilkington, D. McCulloch, K. Latham, J. DuPlessis, Nitriding of high speed steel, Int. Heat Treat. Surf. Eng. 5 (2011) 69-72

[28] R. Rodriguez-Baracada, J.A. Benito, E.S. Puchi-Cabrera, M.H. Staia, High temperature wear resistance of (TiAI)N PVD coating on untreated and gas nitrided AISI H13 steel with different heat treatments, Wear 262 (2007) 380-389

[29] F. Hakami, A. Pramanik, A.K. Basak, Duplex surface treatment of steels by nitriding and chromizing, Aust. J. Mech. Eng. 15 (2017) 55-72

[30] A.F. Rousseau, J.G. Partridge, Y.M. Goezuekara et al., Carbon evolution during vacuum heat treatment of high speed steel, Vacuum 124 (2016) 85-88

[31] B.D. Beake, N. Li, Ch. Gey et al., Wear performance of different PVD coatings during hard wet end milling of H13 tool steel, Surf. Coat. Technol. 279 (2015) 118-125

[32] P.L. Ge, M.D. Bao, H.J. Zhang, K. You, X.P. Liu, Effect of plasma nitriding on adhesion strength of CrTiAlN coatings on H13 steels by closed field unbalanced magnetron sputter ion plating, Surf. Coat. Technol. 229 (2013) 146-150

[33] S. Yongyao, T. Liangliang, H. Rong, Effect of sputtering current on the comprehensive properties of $(\mathrm{Ti}, \mathrm{Al}) \mathrm{N}$ coating and high-speed steel substrate, J. Mater. Eng. Perform. 27 (2018) 2381-2387

[34] J.Y. Xu, Z.Q. Liu, G.Q. Guo, M. Chen, An investigation on wear mechanism of high-speed turning of free-cutting steel AISI 1215 using uncoated and multi-layer coated tools, Int. J. Adv. Manuf. Technol. 67 (2013) 517-533 
[35] S.N. Grigoriev, A.S. Metel, M.A. Volosova, Yu.A. Melnik, Deposition of wear-resistant coatings using a combined source of metal atoms and fast gas molecules, Mech. Ind. 16 (2015) 705

[36] S.N. Grigoriev, A.S. Metel, M.A. Volosova, Yu.A. Melnik, Surface hardening by means of plasma immersion ion implantation and nitriding in glow discharge with electrostatic confinement of electrons, Mech. Ind. 16 (2015) 711

[37] A.A. Vereschaka, M.A. Volosova, A.D. Batako et al., Development of wear-resistant coatings compounds for high-speed steel tool using a combined cathodic vacuum arc deposition, Int. J. Adv. Manuf. Technol. 84 (2016) 1471-1482

[38] M.M. Stebulyanin, A.A. Gurkina, A.A. Shein, N.Y. Cherkasova, Measuring adhesive bond strength and microhardness of multilayer composite wear-resistant coating, Mech. Ind. 17 (2016) 712

[39] V.V. Kuzin, M.Y. Fedorov, P. Dašiæ, Stressed state of boundary between tic/tin-coating layers applied to nitride ceramic under action of a force load, Refract. Ind. Ceram. 58 (2018) 338-342

[40] C.-F. Wang, S.-f. Ou, S.-Y. Chiou, Microstructures of TiN, TiAlN and TiAlVN coatings on AISI M2 steel deposited by magnetron reactive sputtering, Trans. Nonferrous Met. Soc. China 24 (2014) 2559-2565

[41] K.T. Cho, Y.-K. Lee, W.B. Lee, Wear behavior of AISI D2 steel by enhanced ion nitriding with atomic attrition, Tribol. Int. 87 (2015) 82-90
[42] Y. Sato, H. Matsuoka, A. Kubo, et al., Influence of watermiscible cutting fluid on tool wear behavior of various coated high-speed steel tools in hobbing, AIP Conf. Proc. 1835 (2017) 020033

[43] M. Bar-Hen, I. Etsion, Experimental study of the effect of coating thickness and substrate roughness on tool wear during turning. Tribol. Int. 110 (2017) 341-347

[44] G. Skordaris, K.D. Bouzakis, T. Kotsanis, P. Charalampous, E. Bouzakis, O. Lemmer, S. Bolz, Film thickness effect on mechanical properties and milling performance of nanostructured multilayer PVD coated tools, Surf. Coat. Technol. 307 (2016) 452-460

[45] V. Braic, C.N. Zoita, M. Balaceanu et al., TiAlN/TiAlZrN multilayered hard coatings for enhanced performance of HSS drilling tools, Surf. Coat. Technol. 204 (2010) 1925-1928

[46] A.S. Metel, S.N. Grigoriev, Yu.A. Melnik, V.P. Bolbukov, Broad beam sources of fast molecules with segmented cold cathodes and emissive grids, Instrum. Exp. Tech. 55 (2012) $122-130$

[47] A.S. Metel, S.N. Grigoriev, Yu.A. Melnik, V.V. Prudnikov, Glow discharge with electrostatic confinement of electrons in a chamber bombarded by fast electrons, Plasma Phys. Rep. 37 (2011) 628-637

[48] M.A. Volosova, V.D. Gurin, Influence of vacuum-plasma nitride coatings on contact processes and a mechanism of wear of working surfaces of high-speed steel cutting tool at interrupted cutting, J. Frict. Wear 24 (2013) 183-189

Cite this article as: V. Kuzin, V. Gurin, A. Shein, A. Kochetkova, M. Mikhailova, The influence of duplex vacuum-plasma treatment on the mechanics of complex-profile cutting tool wearing in the production of aircraft engine parts, Mechanics \& Industry 19, $704(2018)$ 